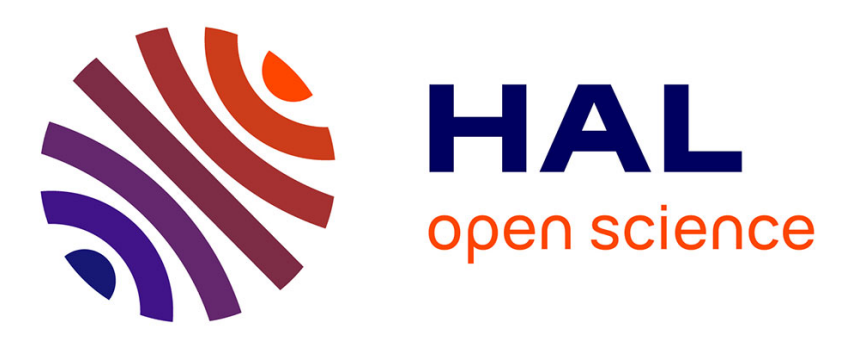

\title{
Design and numerical assessment of a passive electron emitter for spacecraft charging alleviation
}

\author{
J.C. Matéo-Vélez, M. Belhaj, J.F. Roussel, D. Rodgers
}

\section{To cite this version:}

J.C. Matéo-Vélez, M. Belhaj, J.F. Roussel, D. Rodgers. Design and numerical assessment of a passive electron emitter for spacecraft charging alleviation. Spacecraft Charging Technology Conference 2014 (13th SCTC), Jun 2014, PASADENA, United States. hal-01081340

\section{HAL Id: hal-01081340 \\ https://hal.science/hal-01081340}

Submitted on 7 Nov 2014

HAL is a multi-disciplinary open access archive for the deposit and dissemination of scientific research documents, whether they are published or not. The documents may come from teaching and research institutions in France or abroad, or from public or private research centers.
L'archive ouverte pluridisciplinaire HAL, est destinée au dépôt et à la diffusion de documents scientifiques de niveau recherche, publiés ou non, émanant des établissements d'enseignement et de recherche français ou étrangers, des laboratoires publics ou privés. 


\title{
Design and numerical assessment of a passive electron emitter for spacecraft charging alleviation
}

\author{
J.-C. Matéo-Vélez, M. Belhaj, J.-F. Roussel, D. Rodgers
}

\begin{abstract}
In this paper, we examine the theoretical basis for using passive unheated electron field emitters to control hazardous levels of spacecraft charging. We present the experimental evidence relating to the capabilities of passive and low power active field emitters. A new concept of passive field emitters is detailed looking at their characteristics and location on a model satellite typical of a commercial geostationary satellite. The assessment is performed by means of numerical simulations. The generation and extraction of electrons is simulated at micrometric scale. Their flow is modeled at spacecraft scale to assess spacecraft absolute and differential charging alleviation. The system shows good promises limiting the inverted voltage gradient situations, observed especially on solar panels where cover glasses are more positive than solar cells. This situation is known as very risky in-flight, possibly leading to sustained secondary arcing powered by the photovoltaic solar arrays themselves. Finally, we review how existing design practice would be modified by the presence of such passive emitters
\end{abstract}

Keywords-passive electron emission, field-effect, FowlerNordheim, secondary electron emission

\section{INTRODUCTION}

Spacecraft in the Earth's outer magnetosphere, including geostationary orbit (GEO), and in the magnetospheres of some other planets, including Jupiter and Saturn are subjected to high levels of surface electrical charging, sometimes up to many kilovolts of negative potentials. It is also the case in polar low Earth orbit (PEO). Large dielectric areas are exposed to the external environment, with the possibility to create a huge differential potential. This can result in electrostatic discharges (ESD) between surface elements. Most common damaging events caused by ESDs are obtained in the so-called inverted voltage gradient (IVG), in which the metallic spacecraft body is negative w.r.t. to covering dielectrics. Such ESDs can generate several types of defects or damage to a satellite.

Over many years, spacecraft designers have developed mitigation techniques in order to limit the spacecraft absolute and differential charging ([1]-[2]). This includes techniques such as applying metallic coating and grounding as many surfaces as possible, and choosing surface materials with high secondary electron emission by electron impact. In severe substorm conditions however, these techniques are not

J.-C. Matéo-Vélez, M. Belhaj and J.-F. Roussel, are with ONERA - The French Aerospace Lab, Toulouse, France (e-mail: Mateo@onera.fr)

D. Rodgers is with the European Space Agency / ESTEC, Noordwijk, The Netherlands (e-mail: David.Rodgers@esa.int) completely effective and high level of charging can be obtained. Another technique consists in the artificial neutralization of the spacecraft absolute and differential charging.

In this context, an alternative solution could consist in using a passive (or low power) electron emitter. The physical process supporting such an idea is electron field emission, which ignites if the electric field at the surface of a metallic element is greater than $10 \mathrm{MV} / \mathrm{m}$ typically. To obtain such magnitudes, the field must be enhanced by microscopic irregularities. In this domain, the Spindt cathode system (composed of a large number of small and sharp tips) [3] or carbon nanotubes [4] are seen as attractive technologies for low power field emission. The disadvantages of these systems rely on their complex spacecraft integration (voltage and current control in closed loop) and their energy consumption. Another promising technology operates in a completely passive manner, utilizing the field enhancement at the triple junction formed at the interface of metal and insulator exposed to space [5]. The disadvantage of this latter system relies on the potential difference between the anode and the cathode (passively induced by the environment) needed to trigger electron emission, which was more than $1.2 \mathrm{kV}$. This level does not really prevent ESDs to occur somewhere else on the spacecraft.

In this paper, we present a new concept of passive electron emitter aiming at reducing spacecraft charging: the Spacecraft Charging Alleviation by Passive Electron Emitter (SCAPEE) system. Section II presents the SCAPEE characteristics and Section III its numerical assessment. Section IV proposes a summary of how existing design practices may be modified by the presence of the system on-board and presents the perspectives to this work.

\section{DESIGN CONCEPT}

\section{A. Overview}

Fig. 1 presents the general overview of the SCAPEE system. It consists in a series (repetition) of the same pattern: an emitting cathode (C), an extracting anode (A) and a mask (M) in between. The emitter is a tip (T) covered with a material with good electric field amplification capabilities, explained in Part II-B. A series of such emitters is located on the cathode support (C), with a matrix shape for instance, in order to multiply the emission current. The tip is electrically connected to the cathode. (C) is electrically connected to spacecraft ground, possibly through a resistor component or resistive layer. (A) is conductive and disconnected from (C) and (M), and covered by a thin layer with specific properties, explained in Part II-C. (M) is connected to (C). The objective is to 
(Abstract No 146)

generate electrons only by passive means and to direct them towards the ambient plasma in order to obtain a smooth spacecraft discharging (in opposition to sudden and dangerous ESDs). The current from the cathode to the anode must be minimized and its effect very well controlled or at least compensated. The electron current to the mask is considered as lost.
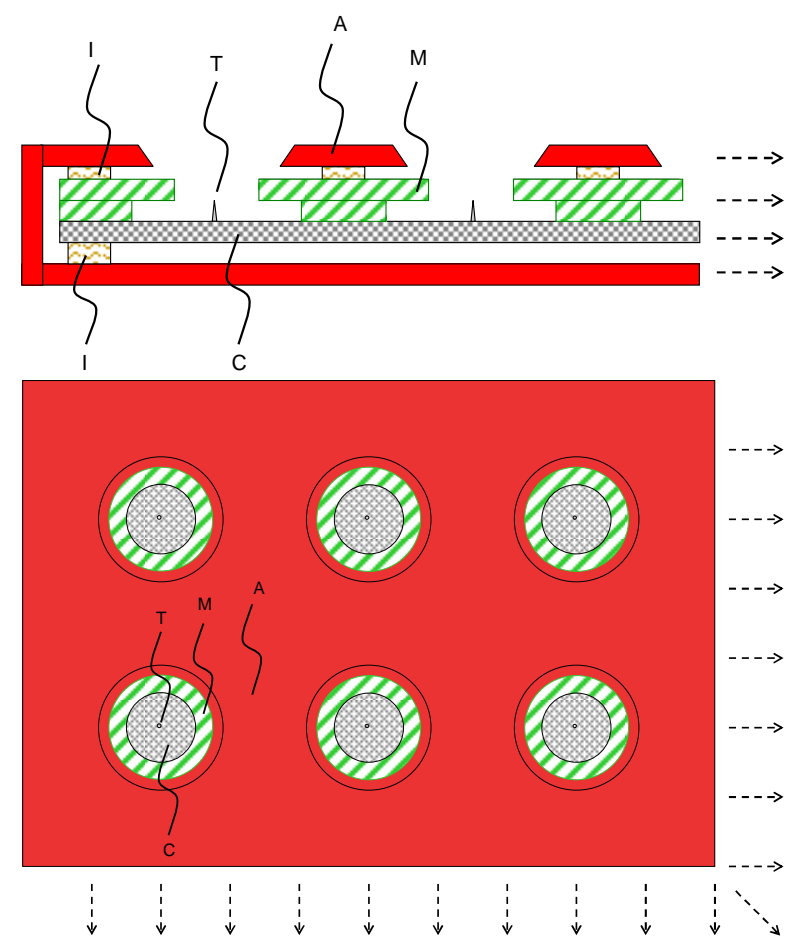

Fig. 1. Schematic overview of SCAPEE system. Top view is a cutting of the bottom figure. The arrows indicate that the design pattern is repeated n-times.

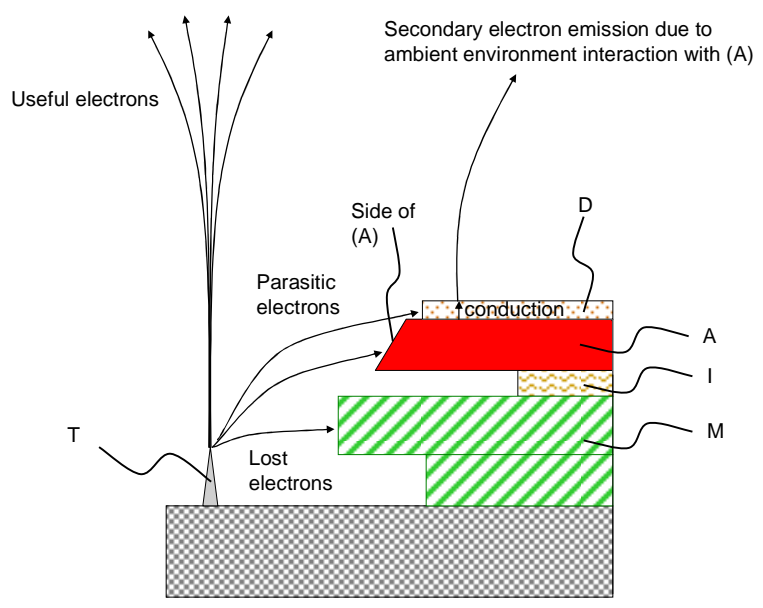

Fig. 2. Possible electron trajectories from their emission at tip level.

The SCAPEE system is composed of two series of findings. In Part II-B, we describe the method proposed to increase the electric field at cathode level. In Part II-C, we describe how the voltage difference between the anode and cathode is obtained and maintained in passive mode. These two elements are independent from each other and can possibly be used to improve other systems such as [3]-[4]-[5].

\section{B. Local Electric Field Amplification}

Given a potential difference at "large" scale between the anode and cathode, the first difficulty is to enhance the electric field at the tip in order to generate field effect emission, whose physical mechanism is sketched in Fig. 3. Electrons in solid material are bounded to the core atoms via the electrostatic force. The potential barrier induced by the electrostatic force is called work function $(W)$ for metals or electronic affinity for dielectrics and semiconductors $(\chi)$. To be emitted into the vacuum, electrons must overcome this barrier. Thus, electron emission may be produced using two ways: 1/ Increasing the temperature (thermo emission) or with particles irradiation (photoemission, secondary electron emission) and; 2/ Lowering the potential barrier at the material/vacuum interface with the help of an applied electric field, in order to allow the tunneling of the quasi-thermalized electrons through the barrier. This latter mechanism is of interest for this work.

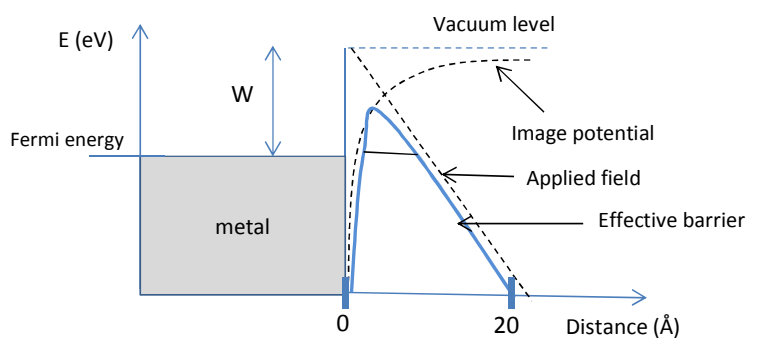

Fig. 3. Electric Field Emission mechanism at metal/vacuum interface

The Fowler-Nordheim equation [6] describing the evolution of the emitted electron current density $J_{F N}$ has been verified theoretically and experimentally:

$$
J_{F N}=\frac{C_{1} F_{t}^{2}}{W} \exp \left(\frac{-C_{2} W^{3 / 2}}{F_{t}}\right)
$$

where $C_{1}$ and $C_{2}$ are constants, $W$ is the material work function and $F_{t}=\beta E$ is the electric field amplified at the tip ( $E$ being the macroscopic field and $\beta$ the geometrical amplification factor). The best emitter materials have the lowest $W($ or $\chi)$ and also the highest enhancement factor. $W$ (or $\chi)$ is an intrinsic surface material property. $\beta$ is highly dependent on the cathode geometry and the material surrounding the cathode (including the anode).

The proposed concept relies on covering (part of) the tip with a material layer made of carbon nano-tubes (CNT). As of today, $\beta$ amplification factor of about 2500 are feasible using CNT carpets. Applying such carpets on sharp tips, of typical dimensions some tens or hundreds of micrometers, may lead in near future to large electric field amplification, due to the multiplication of both tip and CNT factors ([7]-[8]). The second advantage of this cathode design is the better control of the electron emission area, as compared to ([4]-[5]). 


\section{(Abstract No 146)}

\section{Obtaining and Maintaining Passive Voltage}

The second challenge relies on the generation of a large potential between the anode and the cathode only by passive means, i.e. without power supply. It is proposed to use the ambient environment interaction with the system. The basic physical process at play is the electron emission due to the impact of ambient radiations (electrons, protons and/or photons). An anode with good emission properties can float positive wrt to other spacecraft elements, in particular the cathode. Generally, dielectrics have better emission properties than conductors. However, they have the main drawback to produce inhomogeneous potentials due to their low electrical conduction. The system would therefore suffer from two kinds of defects. First the environmental conditions may be not uniform over the anode surface, especially the side facing the cathode (which has all chances to be only partly at Sun). This may lead to an asymmetry of the anode charging and so on to deflect electrons emitted by the cathode, see the so-called parasitic electrons of Fig. 2. The second defect arises from the collection of those parasitic electrons onto the dielectric anode. It results in a local change of the anode potentials, negative of positive pending on the number of secondary electrons generated by this impact. A yield greater than unity will produce the amplification of the electric field, similarly as what is observed in [5], where a pre-breakdown situation is obtained. However, this is quite risky a situation since it may lead to ESD if the current rises too much.

In this work, we chose to use a metallic anode covered with a thin dielectric layer with high electron emission yields under environment irradiations, see Fig. 2. The layer must also be thin enough in order to be sufficiently conductive, to minimize potential differences between the anode and the covering layer. This depends on the nature of the layer. Possible candidates are diamond or Indium Tin Oxyde (ITO). Diamond deposit is known to efficiently conduct trapped charges (electrons, holes). ITO is known to have a large conductivity and electron emission yields.

The third technical problem relies on ensuring that the anode will charge positive in a large range of configurations. Several solutions are proposed. The first one consists in spacing the cathode pin systems from each other and use large anode surafces in between, to avoid that the cathodes negative charge provokes interpenetrating barriers of potentials. The anode must have the capability to emit electrons and should recollect only very few of them. This was evidenced for instance in [9]. The second solution consists in embedding the SCAPEE system in a so-called enveloping anode. This metallic envelope is deployed all around the SCAPEE case. The best approach is to use a material with large electron emission yield, as for the anode described earlier and to connect them electrically. This will permit to benefit from electron emission whatever the orientation of the Sun for instance. This will help getting a positive anode potential on a large range of configurations. The third solution consists in locating several SCAPEE systems all around the spacecraft to multiply the currents, but also to benefit from photoelectron emission most of the time. The fourth solution consists in locating the systems as far as possible from any negatively charged spacecraft surface. Indeed, the anode positive potential is also limited by electron recollection due to negative potential barriers around it, which would be detrimental to the evacuation of the electrons emitted by the anode. Ideally, with a system located at infinite, the anode would float to the plasma potential, i.e. close to zero volts (the spacecraft and cathode being charged negative). On a real case, some locations are thought promising: close to the end of SA (always facing the Sun, except during eclipse), or at the end of long booms, as shown in Part III.B.

\section{Avoiding Risks}

The proposed system finally does not need any control system since the loop between the environment, spacecraft and anode potentials and electron emission by the cathode is a closed loop. There is no risk to generate for instance (too) large electron fluxes with a (too) large energy that may produce equipment defect by electron return on a transient positive spacecraft voltage (generated by such a large flux of energetic electrons) as was unfortunately observed in [10]. In the present system, electrons have a maximal energy corresponding to the potential between the anode and the cathode. As the anode maximal potential is close to zero volts, there is no risk that the cathode electrons can return back to the spacecraft, except of course if the system directly fires towards the spacecraft (which is easy to avoid).

\section{E. Resisting to Space Environment}

The spacecraft is inevitably exposed to ambient atmosphere. The emitter oxidation and contamination is an important issue that has to be addressed. Indeed, the surface modifications may lead to significant work function changes affecting the threshold emission of the cathode. This was illustrated in the case of Mobdylenium, where the oxide layer removing with laser annealing shifted the threshold field from $65 \mathrm{~V}$ to 55 Volts [11]. Nano-tubes and diamond are less sensitive to contamination due to the low chemical reactivity of their surface.

Micro-tip sharpness, height and surface work function disparities will certainly result on emission current variation from one tip to another. Sharper tips and tips with lower work functions may generate larger currents and in extreme cases may be damaged due to excessive heating as illustrated in [12]. The problem may be solved by placing a resistor between the emitter and the cathode electrode under the emitter. The function of this resistor is to limit the current emitted by the micro-tip. It tends to normalize the emission current for all tips. Another strategy for improving the uniformity is to introduce redundancy by increasing the number of tips per pixel. The current contribution per tip is reduced and the operating voltage should be lowered.

The temperature may have an impact on the threshold voltage leading to passive emission at cathode level. During emission, due to Joule effect, we could also observe outgasing, which could possibly lead to ionization under cathode to anode differential potential. Such "self-generation" of ions may produce cathode bombardment and degradation. The temperature could also influence the anode covering layer properties. Indeed, the electron conductivity drops rapidly at low temperature. Using very thin layers is thus required. 
(Abstract No 146)

Finally, cathode coating with nano-tubes is questionable, when looking at atomic oxygen bombardment in LEO. In GEO, the risk is significantly reduced.

\section{NUMERICAL ASSESSMENT}

The SCAPEE concept is assessed in two steps. In Part IIIA, we numerically simulate several configurations and optimized them. In Part III-B, we simulate a spacecraft immersed in GEO charging environment and equipped with an optimized system.

\section{A. Simulation at Microscopic Scale}

The concept was optimized using the Spacecraft Plasma Interaction Software (SPIS) [13]. The axisymmetric geometry used is reported in Fig. 4.

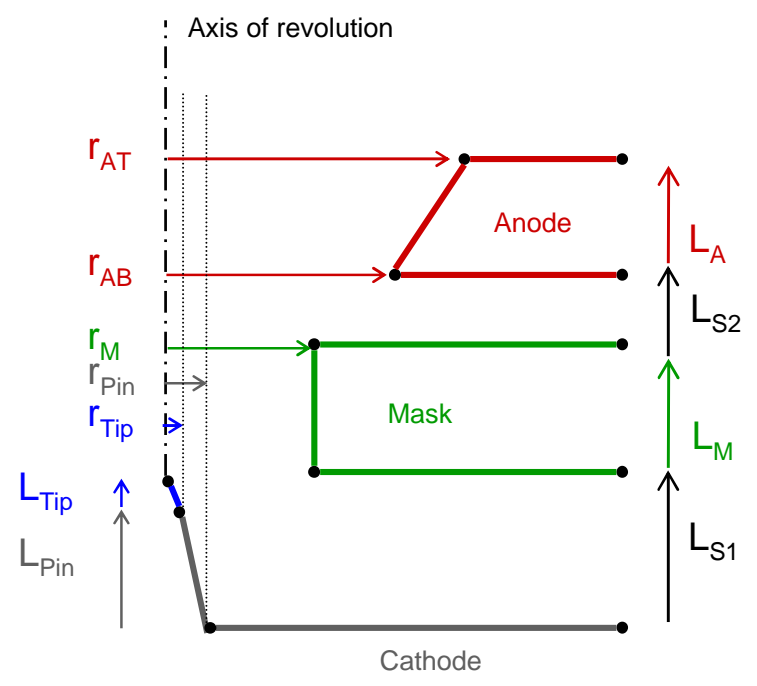

Fig. 4. Parameters defining the dimensions of the anode, mask, cathode and tip.

It was supposed that the anode is conductive. The FowlerNordheim equation (1) was used to model electron emission on the tip, taking a work function of $4.5 \mathrm{eV}$. The $\beta$ amplification factor obtained by CNT is assumed to be equal to 2500. The Poisson equation is solved to compute the "macroscopic" electric field amplification imposed by the tip and overall system geometry. Electrons dynamics is computed with a Particle-in-Cell approach. The cathode and mask are set to the same potential. The anode to cathode voltage follows a sweep in order to find out the threshold for current emission. The top external boundary is an open boundary for electrons (loss). The potential on the top boundary was successively changed from anode voltage (typical of sunlit surface potential induced by potential barriers in GEO), into a $1 / \mathrm{r}$ decrease typical of vacuum. The use of either one or another did not lead to very significant changes, since they have a second order (but not completely negligible) impact on the potential map close to the cathode tip and anode aperture.

A parametric study was performed on the emitter geometry. An illustration of a bad behavior is given in Fig. 5 in which the electrons emitted by the cathode tip are predominantly collected by the anode. This of course would lead to the collapse of the anode floating potential, in real case. The study consecutively looked at the effect of the tip length and sharpness, dimensions of the mask, anode hole and thickness. We concluded that a smooth tip is preferable than a very sharp one to obtain an emission preferentially directed towards the top (and not towards the mask and anode). The tip should be placed below the anode and not in the middle of it. The use of a mask is necessary. The anode hole should be large enough and preferentially with a shaped pattern as in Fig. 4.

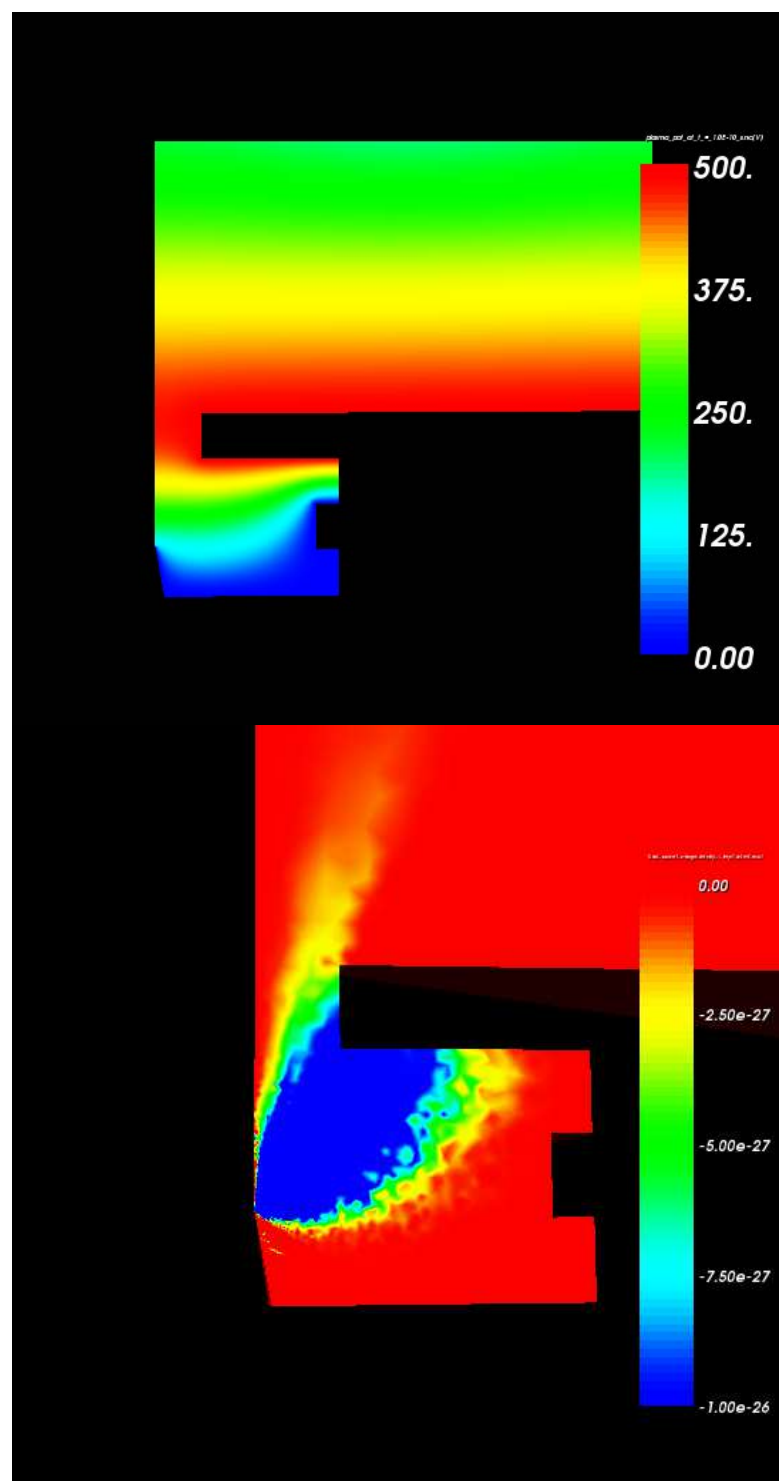

Fig. 5. Electric potential map (top) and corresponding electron charge density (bottom, blue color corresponds to large densities). Basic configuration.

An optimized configuration is given in Fig. 6. This configuration, whose geometry details are reported in Fig. 7, led to a negligible collection onto the anode. Electron trajectories demonstrate the electrostatic lens behavior. Between the cathode and mask, the flux first diverges due to an almost isotropic emission at the tip extremity. Then, it 
(Abstract No 146)

converges slightly before the mask aperture because the anode attractive influence gets inside this aperture. Electrons get accelerated upward and their directed kinetic energy prevents them from being deflected too much towards the anode.

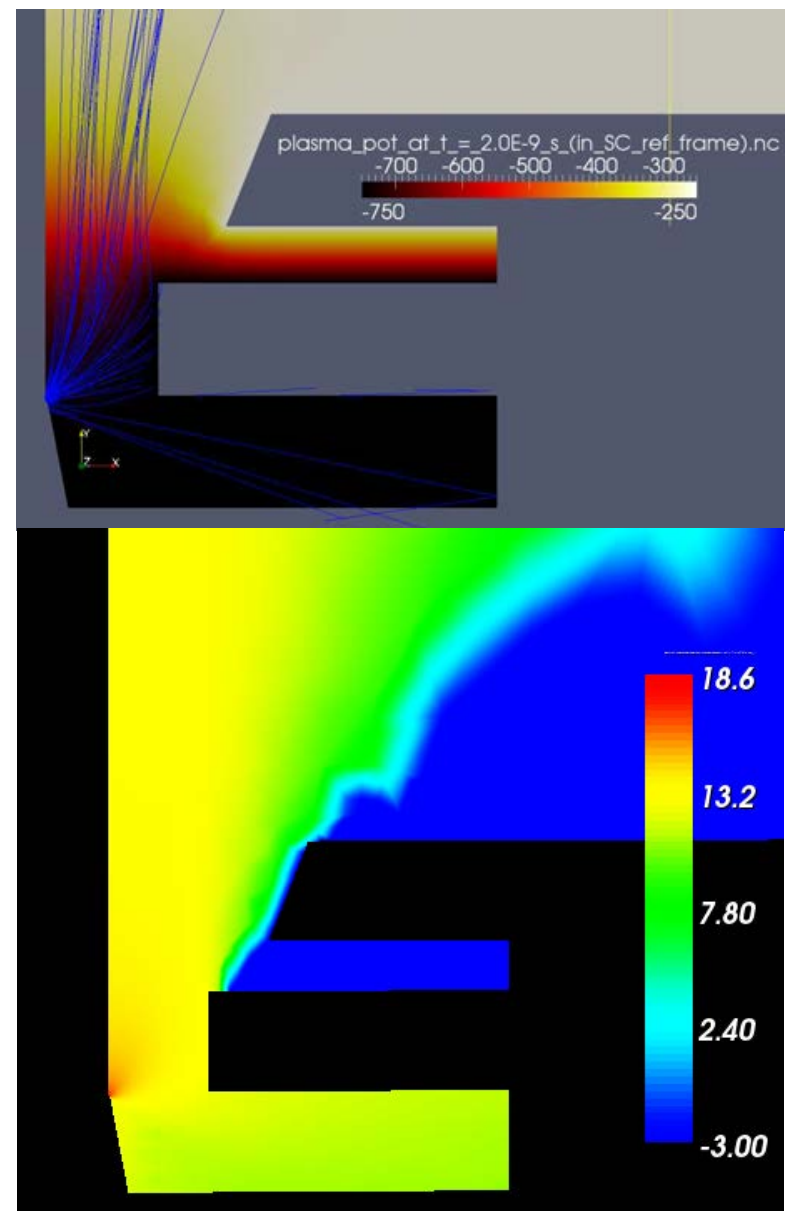

Fig. 6. Top: Electric potential map and some electron trajectories for an anode to cathode voltage of $+500 \mathrm{~V}$. Bottom: $\log 10$ of electron density for a voltage of 680 Volts. Optimized configuration.

\begin{tabular}{|c|r||c|r|}
\hline Radius & \multicolumn{1}{|c||}{$[\mathrm{m}]$} & Length & {$[\mathrm{m}]$} \\
\hline$r_{\text {Tip }}$ & $10 \mathrm{e}-6$ & $L_{\text {Tip }}$ & $10 \mathrm{e}-6$ \\
\hline$r_{P i n}$ & $100 \mathrm{e}-6$ & $L_{P i n}$ & $470 \mathrm{e}-6$ \\
\hline$r_{A, T}$ & $1000 \mathrm{e}-6$ & $L_{A}$ & $500 \mathrm{e}-6$ \\
\hline$r_{A, B}$ & $800 \mathrm{e}-6$ & $L_{M}$ & $500 \mathrm{e}-6$ \\
\hline$r_{M}$ & $500 \mathrm{e}-6$ & $L_{S 1}$ & $500 \mathrm{e}-6$ \\
\hline & & $L_{S 2}$ & $250 \mathrm{e}-6$ \\
\hline
\end{tabular}

Fig. 7. Optimized system dimensions.

An interesting point is the energy and divergence of the electron flux when they escape the anode exit plane, i.e. at $1.75 \mathrm{~mm}$ away from the cathode plane. As shown in Fig. 6, the flux is axisymmetric with a slow divergence of approximately $30^{\circ}$ ( 0.5 radian). The energy of electrons when they escape depends on the local potential, represented in Fig. 8, where the cathode was at potential $-1750 \mathrm{~V}$ and the anode at $-875 \mathrm{~V}$. The maximal theoretical energy of electrons exiting the anode hole is $875 \mathrm{eV}$. However, the potential at anode exit plane is rather between -1040 and $-875 \mathrm{~V}$, meaning energy between 710 and $875 \mathrm{eV}$. The electron mean energy is thus about $800 \mathrm{eV}$ and the energy efficiency about $90 \%$. In Part III-B, it will be thus considered that the electron mean energy is $90 \%$ of the applied difference of potential multiplied by the electron charge, and the energy dispersion will be taken as $10 \%$ of the mean energy. As a conclusion, the flux is close to unidirectional and mono-energetic, which are interesting characteristics.

\section{Potential profile at anode exit}

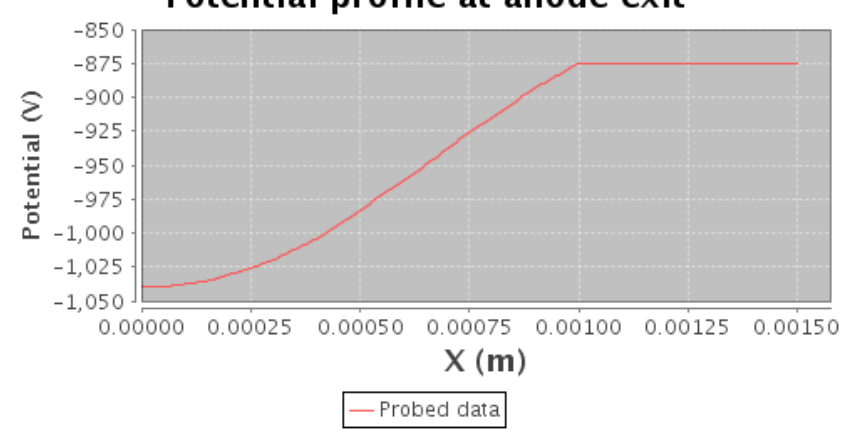

Fig. 8. Potential radial profile at anode exit plane for an anode and cathode potentials of $-875 \mathrm{~V}$ and $-1750 \mathrm{~V}$ respectively.

Finally the current voltage (IV) curve is represented in Fig. 9. A significant current can be achieved with some hundreds volts between the anode and the cathode. It should be able to counterbalance ambient electron collection by the spacecraft (fraction of milliamps in GEO substorms). The impact of the amplification factor $\beta$ is of prime importance to get a lower threshold. Of particular interest, the net current rise follows the equation (1) behavior only for low voltage difference. For large voltages, the current extraction is so high that the electron space charge (larger than $10^{18} \mathrm{~m}^{-3}$ in Fig. 6) does impact the potential map. As a result, it automatically diminishes the electric field at the tip vicinity, see Fig. 10, and so on the extracted current. The simulations performed in this study showed that the current density increases linearly instead of exponentially after this knee point.

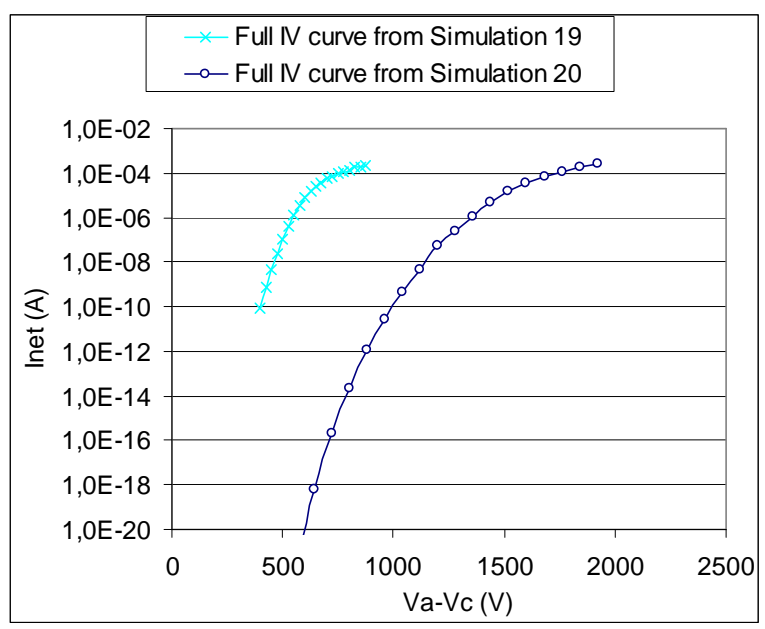

Fig. 9. Net IV curve of the optimized configuration assuming $\beta=2500$ (light blue, "simulation 19")and $\beta=1000$ (dark blue, "simulation 20"). 
(Abstract No 146)

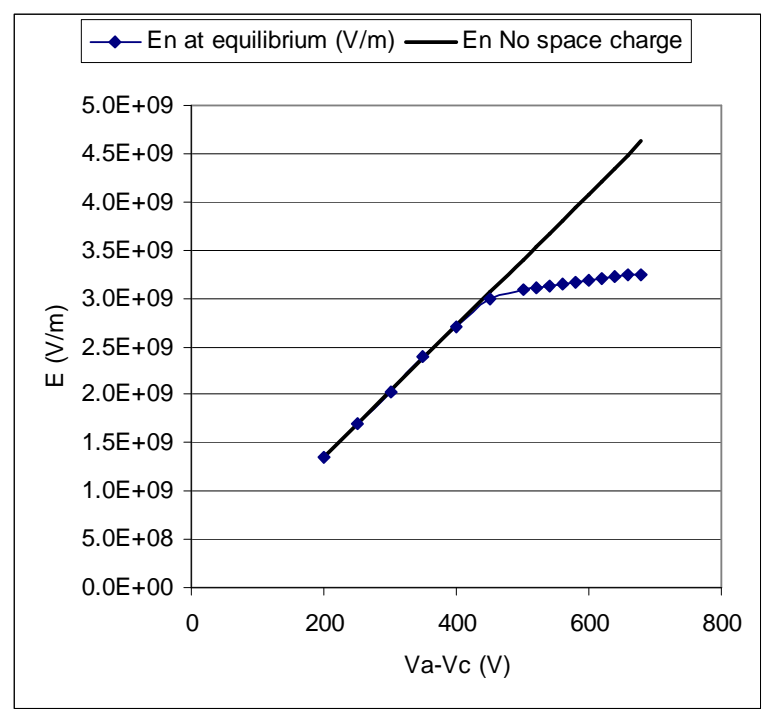

Fig. 10. Maximal electric field as a function of anode to cathode voltage. The solid black curve is theoretical extrapolation of numerical results (squarred line) and assumes no space charge effect.

\section{B. Assessment at GEO Spacecraft Scale}

The effect of the SCAPEE system on global spacecraft charging is assessed through numerical simulations using SPIS. [14]). The spacecraft geometry is described in Fig. 11. It is composed of a conductive spacecraft hub of dimensions $1.76 * 2.64 * 2.64 \mathrm{~m}$ covered with of Indium Tin Oxide material (ITO) except the top and bottom surfaces covered with kapton, two circular antennas of diameter $2.00 \mathrm{~m}$ and thickness $0.15 \mathrm{~m}$ made of graphite, a cylindrical antenna of diameter $1.00 \mathrm{~m}$ and length $0.88 \mathrm{~m}$ made of graphite, and finally two solar arrays (SA) of dimensions $7.04 * 4.40 * 0.15 \mathrm{~m}$ covered with cover glass material (CERS). Materials have default SPIS material properties; see the documentation embedded in SPIS release [13]. The SCAPEE system was modeled as a small cube covered with anode material. This material is assumed to have very good electron emission properties, thus we take the most appropriate SPIS default material, i.e. CERS. The cathode is not modeled by a geometrical surface, since it is covered with the anode.

Several runs were performed with 0/ Emitter located $0.4 \mathrm{~m}$ from the SA, see Fig. 11, but not activated (location \#0); 1/ Activation of an emitter located 2 meters away from the SA (location \#1); 2/ Emitter located above the spacecraft and facing the plasma (location \#2); 3/ Emitter above the spacecraft and facing the SA (location \#3).

The spacecraft is immersed in the ECSS worst-case environment [14].
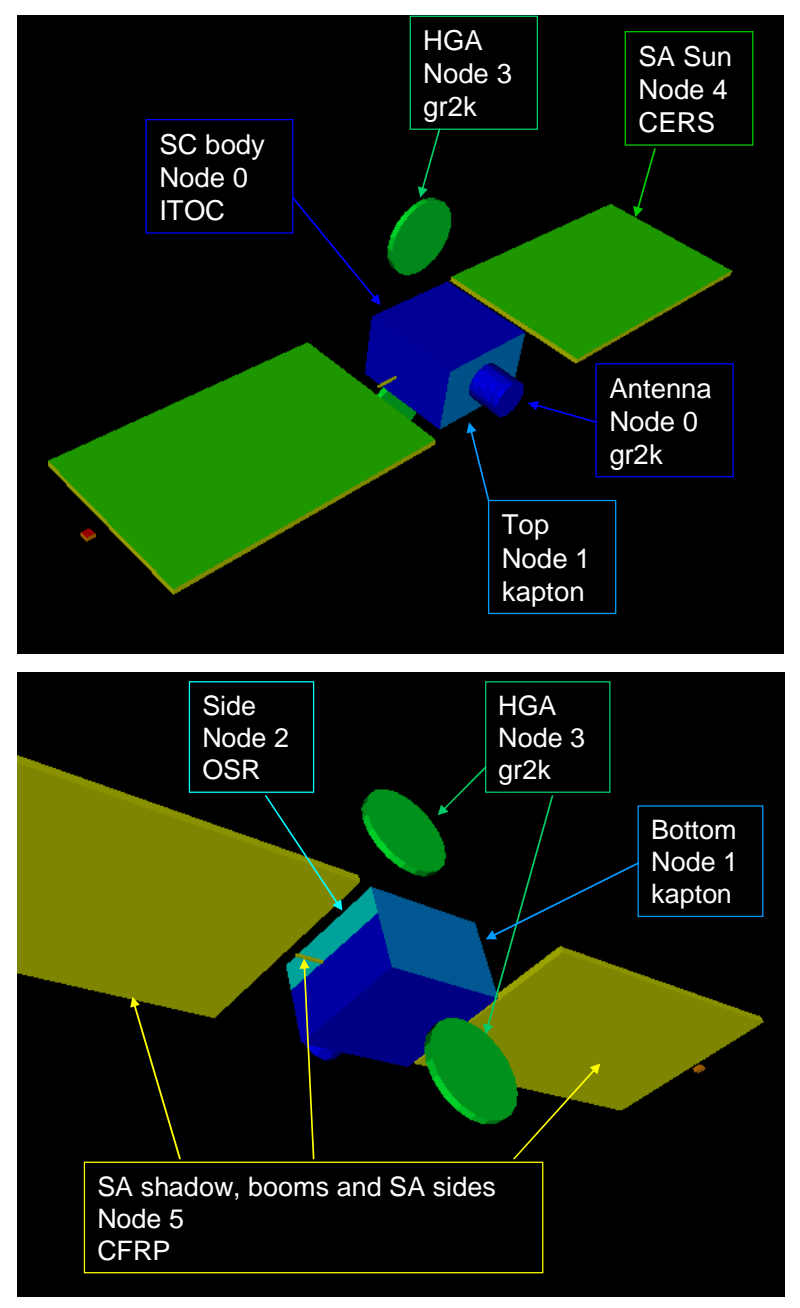

Fig. 11. Spacecraft geometry front and back side, with covering materials. Here the emitter is located 0.4 meter away from the SA.

\section{a) Reference case}

After $1000 \mathrm{~s}$, the spacecraft ground reaches $-5400 \mathrm{~V}$ and the cover glasses -3200 Volts. This corresponds to a $+2200 \mathrm{~V}$ inverted voltage gradient. Of course, this situation may lead to ESDs on the SA. Shaded dielectrics are negative wrt to ground, with a maximum of $-11900 \mathrm{~V}$ for the kapton surfaces, i.e. a normal potential gradient (NPG) of $-6500 \mathrm{~V}$.

The SA potential is more positive far from the spacecraft hub, see Fig. 12, because the influence of the negative spacecraft is less pronounced. Photoelectrons are more easily extracted towards the plasma close to the end of the SA, due to lower barriers of potentials. In this reference case, the best location for emitters would be at this latter place. Indeed, the anode would float to the most positive potential there. In the present simulation at $0.4 \mathrm{~m}$ away from the SA however, the emitter is influenced by the negative potential of the SA rear side, and it floats to a more negative potential of $-3900 \mathrm{~V}$, as shown in Fig. 14. This position would not prevent at all SA to charge at dangerous levels. The location is optimized in further parts. 
(Abstract No 146)

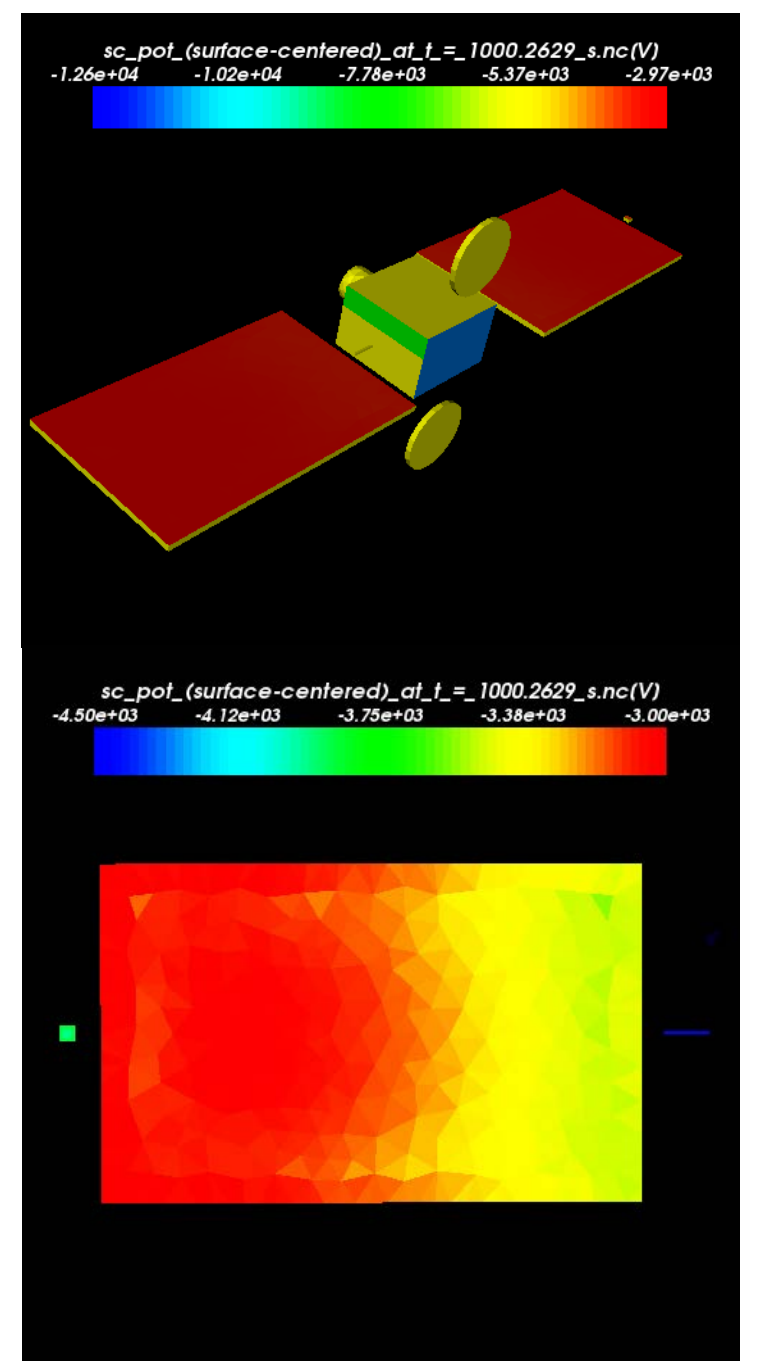

Fig. 12. Top: spacecraft surface potential in the reference case after $1000 \mathrm{~s}$. Bottom: Zoom on the SA and emitter region.

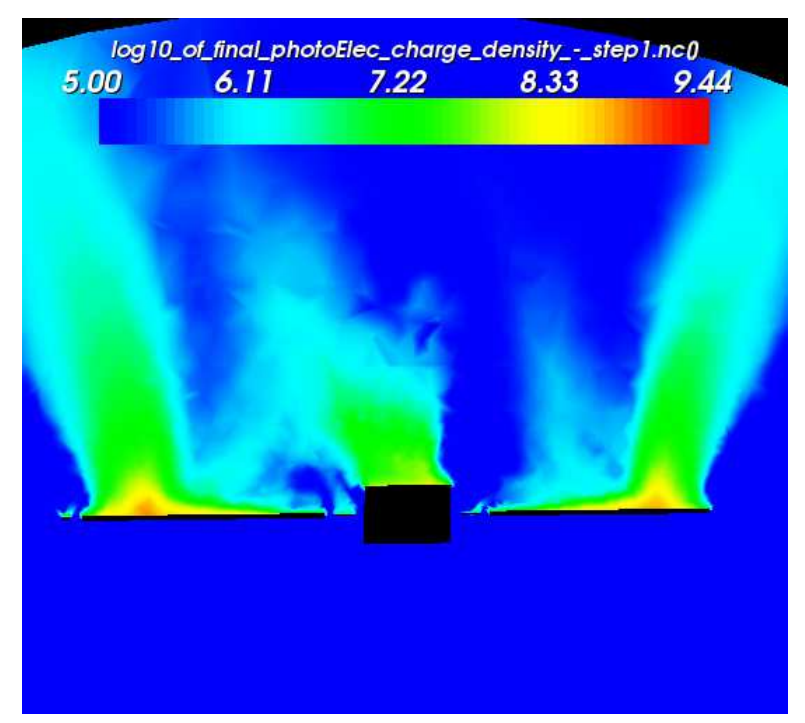

Fig. 13. $\log 10$ of photoelectron density showing the location of electron ejection, close to the end of the SAs.

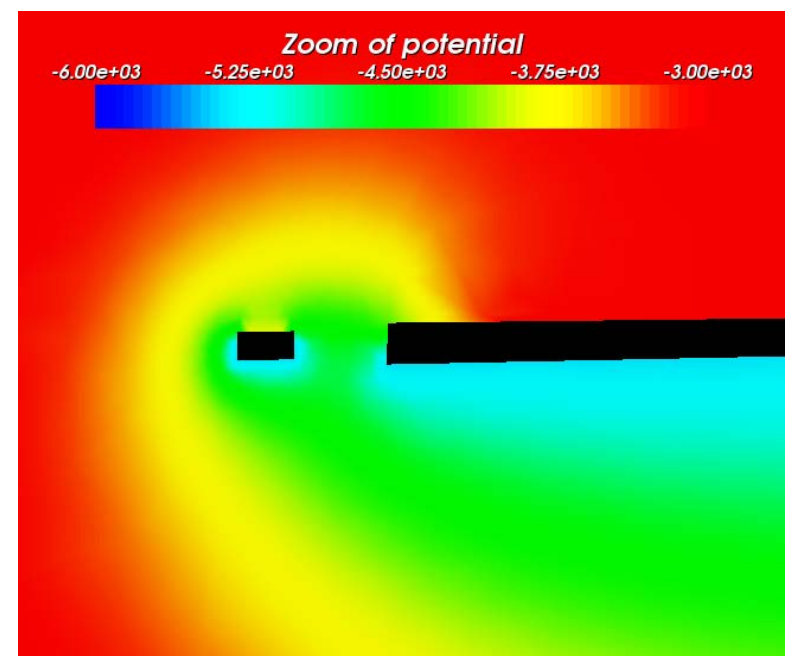

Fig. 14. Emitter potential when at location \#0, showing the negative potential barrier preventing efficient anode charging.

\section{b) Emitter at location 1}

The current-voltage curve obtained with $\beta=2500$ and reported in Fig. 9 are used on the $0.2 \times 0.2 \mathrm{~m}$ top surface of the SCAPEE anode. The current is calculated as a function of the potential between the anode surface and the underlying and grounded cathode. As indicated in Part III-A, the electron mean energy is $90 \%$ of this potential difference multiplied by the electron charge. The energy dispersion is $10 \%$ of the mean energy. The angular dispersion is $0.5 \mathrm{rad}$.

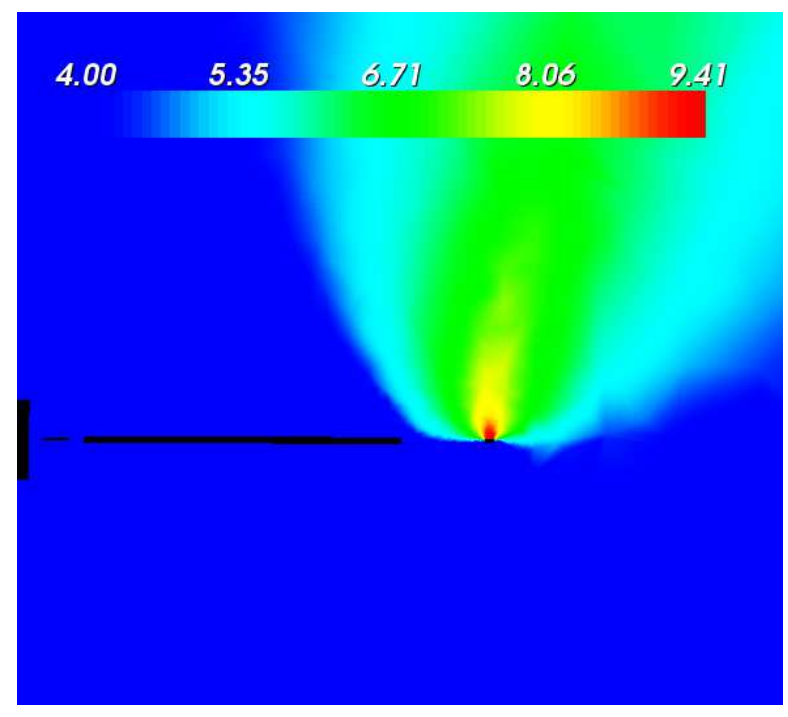

Fig. 15. $\log 10$ of passive emitter electron density, using the emitter at location \#1, i.e. 2 meters away from the SA

After $1000 \mathrm{~s}$, and assuming that ten emitter tips are used ( $\left.250 \mathrm{tips} / \mathrm{m}^{2}\right)$, the IVG level is limited to only $+450 \mathrm{~V}$ on SA. In this condition, the ground is at $-1350 \mathrm{~V}, \mathrm{SA}$ at $-900 \mathrm{~V}$ and anode at $-650 \mathrm{~V}$. The anode is the most positive surface, which shows that is position has been appropriately chosen. Electrons are ejected from the system to the plasma because of their initial kinetic and potential energy. They are then accelerated 
(Abstract No 146)

toward the undisturbed plasma region, with no chance of recollection by the spacecraft.

\section{c) Emitter at location 2}

The system is now located above and at $3.2 \mathrm{~m}$ from the spacecraft hub in the Sun direction. It faces the plasma. Such a position is possibly obtained using booms. It has the advantage to avoid interactions with the SA system (including drive mechanisms). Using a density of $250 \mathrm{tips} / \mathrm{m}^{2}$ leads to a spacecraft ground of $-2150 \mathrm{~V}, \mathrm{SA}$ at $-1400 \mathrm{~V}$ and an anode at $1500 \mathrm{~V}$. This situation is less efficient than location \#1 because the negative spacecraft influence is quite large at location \#2. Of course this influence would decrease when getting further from the hub, using a longer boom.

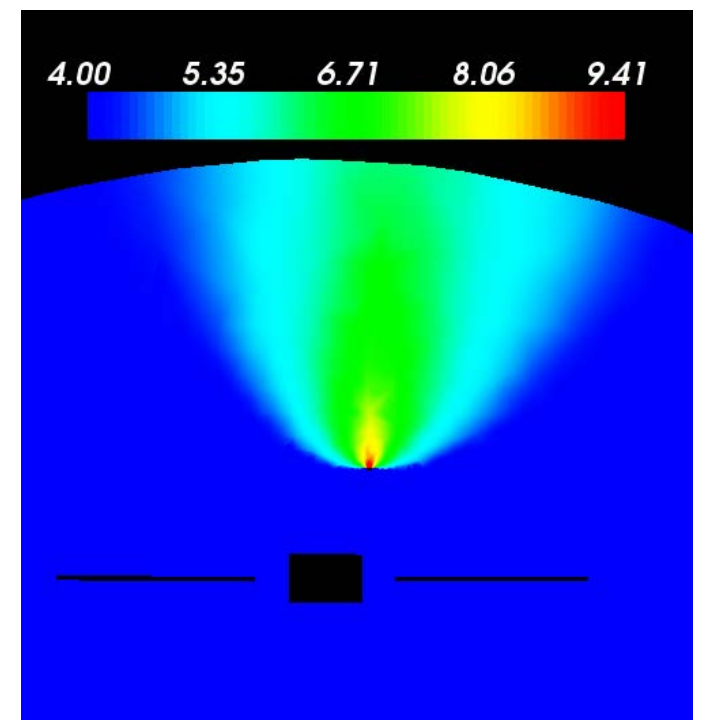

Fig. 16. $\log 10$ of passive emitter electrons density, using the emitter at location \#2, i.e. 3.2 meters above the spacecraft and facing the Sun.

\section{d) Emitter at location 3}

The emitter is at the same location as \#2 but it is rotated to face one SA. This situation aims at determining if SA differential charging may be mitigated by electron collection. Fig. 17 shows however that the emitted electron density is small (smaller than $10^{7} \mathrm{~m}^{-3}$ ) compared to the photoelectron density of Fig. 13 (larger than $10^{8} \mathrm{~m}^{-3}$ ). This current onto SA does not change significantly its potential as compared to the other SA, see Fig. 18. This situation is finally less efficient than location 1 and 2 .

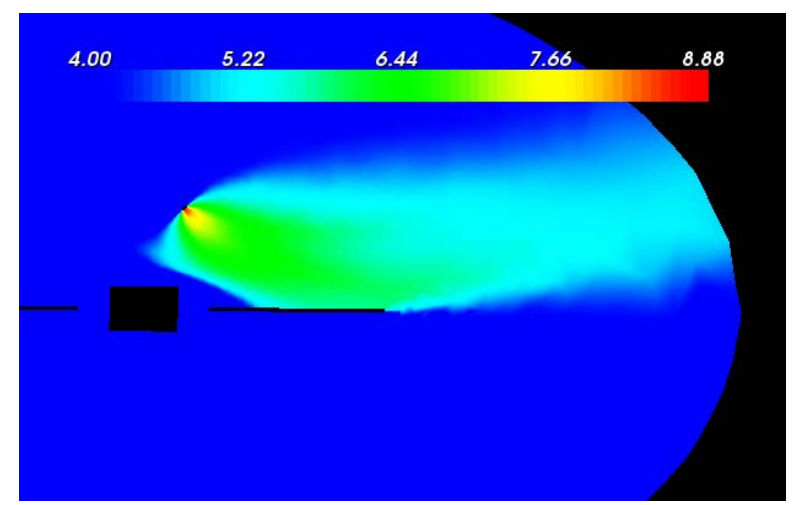

Fig. 17. $\log 10$ of passive emitter electrons density, using the emitter at location \#3

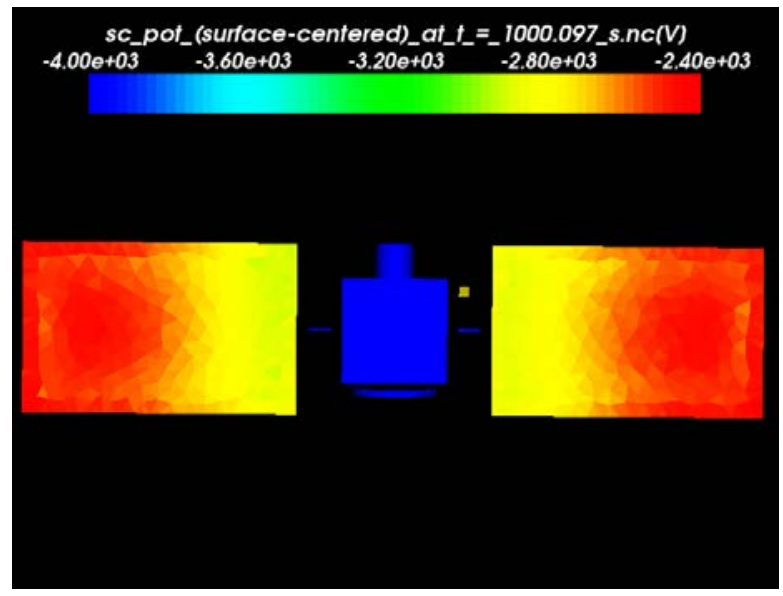

Fig. 18. Spacecraft surface potential with 1 emitter at position.Colour bar is limited to $-4000 \mathrm{~V}$ negative to show SA potential gradients.

\section{SUMMARY}

This paper assesses the conceptual design of a new passive electron emitter, so-called SCAPEE, aiming at reducing spacecraft negative charging. Under the reported conditions, the potentials of the GEO spacecraft used in this study seem possible to control with a limited number of emitters. The inverted voltage gradient is significantly reduced. Because the system is not dependent on the Debye length, if severe negative charging were to occur in PEO, the device would work as in GEO. Probably shorter booms and distance to the spacecraft would be sufficient to get rid off the negative potential barriers, due to more efficient Debye shielding.

At emitter level, it combines the electric field amplification of a tip covered with nano-materials, and the passive generation of anode to cathode voltage. The anode design was shown to be of prime importance as well as the presence of a mask in between. One of the main objectives, i.e. to maintain the anode positive only by passive means (no power supply), seems possible to achieve from the theoretical and numerical assessment performed.

Putting SCAPEE at the end of long booms seems promising. Close to the end of solar arrays is also a good position. The system thermal conductivity, absorption and emissive properties will have to be investigated in order to keep its temperature to acceptable ranges. As long as the system remains small, it should not jeopardize global spacecraft thermal equilibrium. The temperature of the emitter itself should also be investigated, in particular the cathode. It may influence the electron emission at micron scale. Basically, the SCAPEE cathode is connected to the spacecraft ground structure. The necessity to prevent large transient currents arises from the risk of unexpected electron avalanche (for instance provoked by electron colliding with the anode, with subsequent secondary electron emission). The energy released may burn some tips and reduce the efficiency or destroy the unit. The solution would consist in mounting the SCAPEE unit in series with a component resistor, in complement to the 


\section{(Abstract No 146)}

optional resistive sheet between the cathode and the SCAPEE support.

The SCAPEE system may also impact how existing spacecraft charging mitigation techniques are implemented. We can first expect changes concerning passive methods: metal coated dielectrics, high secondary electron emission dielectrics or dielectrics covered with semi-conductive paintings. The differential charging of dielectrics on sunlit faces is reduced by the SCAPEE system. As a result, it could be feasible to decrease the constraints that prevail as of today for material selection. It could help using new materials with more confidence levels. The mitigation proposed in the SCAPEE system tends however to increase the constraints on shaded dielectrics in normal gradient situation, since they still charge to very negative potentials while the ground is limited to less negative voltages. Larger margins may be needed for them.

The SCAPEE system can be seen as a complement to existing active methods described in [1]-[2]:

- Hot filament for emitting electrons. The objective is the same: to reduce the absolute charging and IVG levels. This technique is a bit risky since electrons follow the electric field lines since they have a low energy at emission, with a non negligible risk to strike the spacecraft, with unpredictable effects.

- Electron beam. The objective is the same but electron guns need a series of voltage supply and controls (heated electrode, accelerating anode, grids, focus, etc...). An instrument failure was observed due to control errors [10].

- Ion beam. The emission of an ion beam with a sufficient energy can provoke secondary electron emission and decrease the negative potential of some parts. It could reduce the normal gradient situation. The operation of the ion beam is however complex since ions are emitted towards the plasma and return back to the spacecraft because of its negative potential. Material erosion and contamination must also be addressed.

- Plasma emission is more effective than electron or ion emission alone. It helps discharging both normal and inverted potential gradient. It needs to embark gas tanks and control systems. It must be operated only when necessary and with a sufficiently dense plasma. Erosion and contamination must be addressed.

In near future, it is expected to build a prototype of the system, to test it under GEO-like plasma environment.
Ageing and thermal effects are also key aspects to assess the SCAPEE reliability during the spacecraft lifetime.

\section{ACKNOWLEDGMENT}

This work was supported by ESA (ESTEC Co 4000105753/12/NL/KML).

\section{REFERENCES}

[1] S. T. Lai, "A critical overview on spacecraft charging mitigation methods", IEEE Transactions on Plasma Science, vol. 31, n ${ }^{\circ}$ 6, p. 1118 1124,2003

[2] S. T. Lai, "Fundamentals of Spacecraft Charging: Spacecraft Interactions with Space Plasmas", Princeton Univ. Press, Princeton, New Jersey, USA, 2012.

[3] R. Adamo and V. M. Aguero, "Space applications of spindt cathode field emission devices", Proc. 6th Spacecraft Charging Technology Conf., Hanscom AFB, MA, Nov. 1998.

[4] Y. Okawa, S. Kitamura, S. Kawamoto, Y. Iseki, K. Hashimoto, E. Noda, "An experimental study on carbon nanotube cathodes for electrodynamic tether propulsion", Acta Astronautica 61 (2007) 989 994.

[5] A. R. Khan, T. Sumida, M. Iwata, K. Toyoda, M. Cho, T. Fujita, "Environment Exposure Tests of Electron-emitting Film for Spacecraft Charging Mitigation”, IEEE Trans. Plasma Sci., Vol 40, N2, 2012.

[6] Fowler R.H., Nordheim Dr. L, "Electron Emission in Intense Electric Fields", Proceedings of the Royal Society of London 119 (781): 173$181,1928$.

[7] C. Journet, M. Marchand, J.-M. Benoit, B. I. Yakobson, et S. T. Purcell, "Direct growth of carbon nanotubes atom by atom during field emission", MRS Online Proceedings Library, vol. 1204, 2009.

[8] J. M. Ha, H. J. Kim, H. S. Raza, et S. O. Cho, "Highly stable carbon nanotube field emitters on small metal tips against electrical arcing", Nanoscale Research Letters, vol. 8, no 1, p. 355, Aug. 2013.

[9] P. Sarrailh, J.-C. Matéo-Vélez, J.-F. Roussel, B. Dirassen, J. Forest, B. Thiébault, D. Rodgers, and A. Hilgers, Comparison of Numerical and Experimental Investigations on the ESD Onset in the Inverted Potential Gradient Situation in GEO, IEEE Trans. Plasma Sci., vol. 40, no. 2, Feb. 2012.

[10] M.S. Gussenhoven, E.G. Mullen, SCATHA retrospective : Satellite frame charging and discharging in the near-geosynchronous environment, 6th Spacecraft Charging Technology Conference, AFRLVS-TR-20001578, September 2000.

[11] D. Seo, C.O. Kim, J.P. Hong, J.S. Shin, B.K. Song, S.N. Cha, J.W. Chung, J.M. Kim, H.S. Baik, "Laser-induced surface cleaning of molybdenum field emitter arrays for enhanced electron emission "Appl. Phys. Lett. 82 (2003) 3299.

[12] N.S. Xu, S.E. Huq "Novel cold cathode materials and applications" Mat. Scien. and Eng. R 48 (2005) 47.

[13] http://www.spis.org

[14] ECSS-E-ST-10-04C, http://www.ecss.nl, ECSS Space Environment standard, 2008 


\section{Design and numerical assessment of a passive electron emitter for spacecraft charging alleviation}

J.-C. Matéo-Vélez, M. Belhaj, J.-F. Roussel and D. Rodgers

13th Spacecraft Charging and Technology Conference

Pasadena, CA, 23-27/06/2014
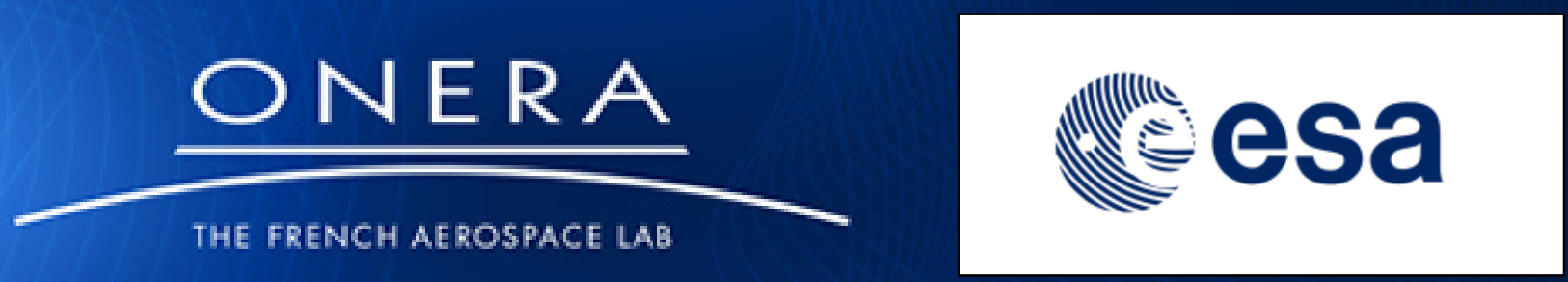

o n i n n o v a t i 0 n 


\section{Context}

- Spacecraft negative charging during GEO substorm, PEO auroral events

- Electrostatic discharges

- Secondary arcing on solar arrays

- Mitigation technique $1=$ to limit the appearance of ESDs

- Material coating

- Grounding conductors

- Neutralization using electron guns, plasma contactors, ion beams

- Mitigation technique 2 = to avoid damaging effects of ESD

- Take margins on solar array design (current, voltage)

- In this work

- New concept for Spacecraft Charging Alleviation by Passive Electron Emission : SCAPEE

- Mitigation technique $1 \rightarrow$ limit ESD appearance 


\section{Some Electron Emitters in Space Industry}

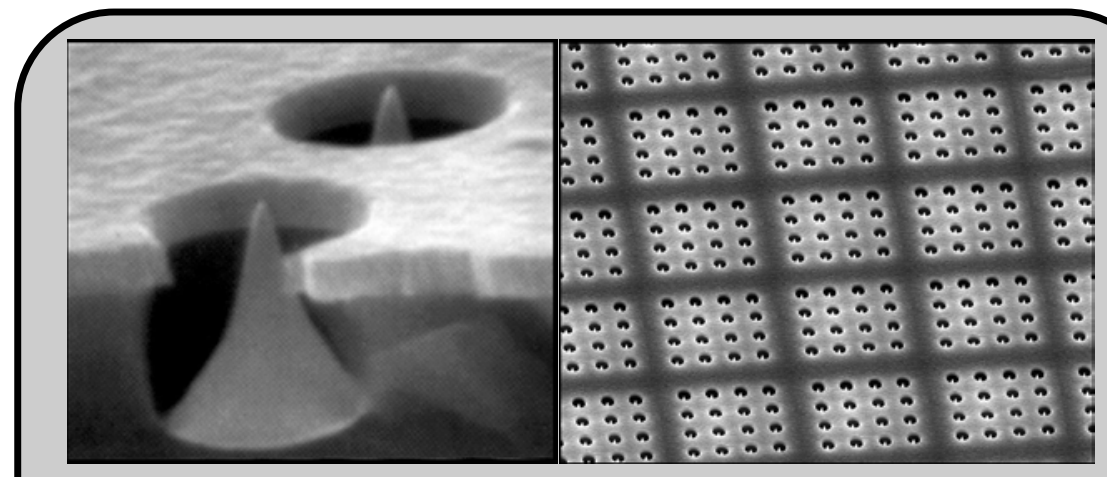

Aguero-Adamo 2002: Active system

Electron field emission at tip level

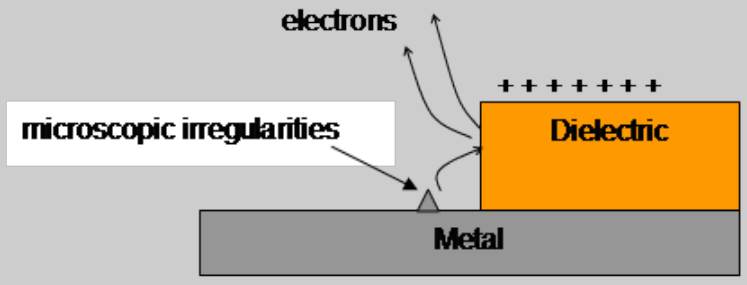

Iwata-2009: Passive system, Ambient Env. charging Pre-breakdown situation at triple point

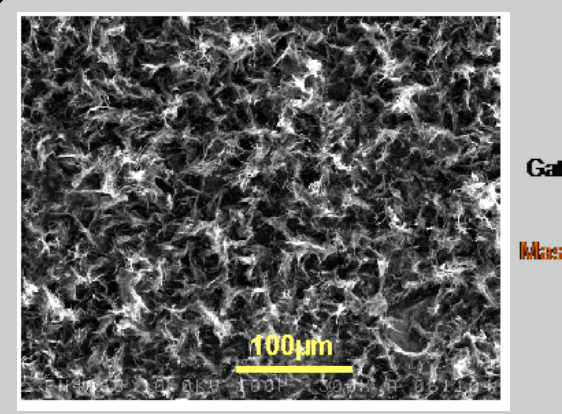

Okhawa-2007: Active system

Electron field emission at Carbon Nano Tube carpet (CNT)

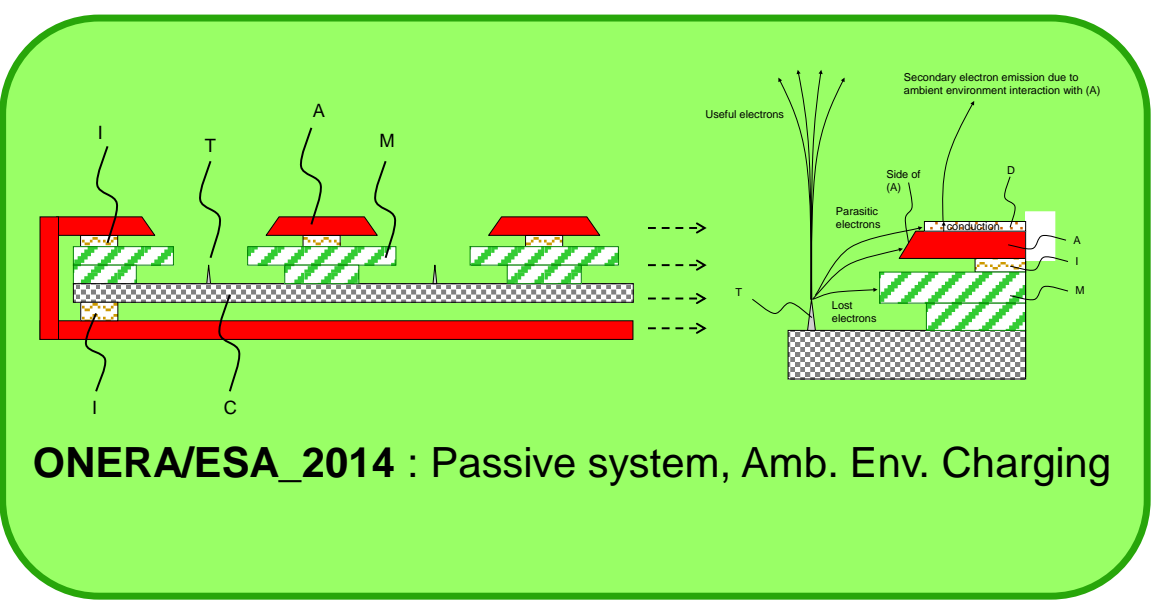




\section{SCAPEE overview}
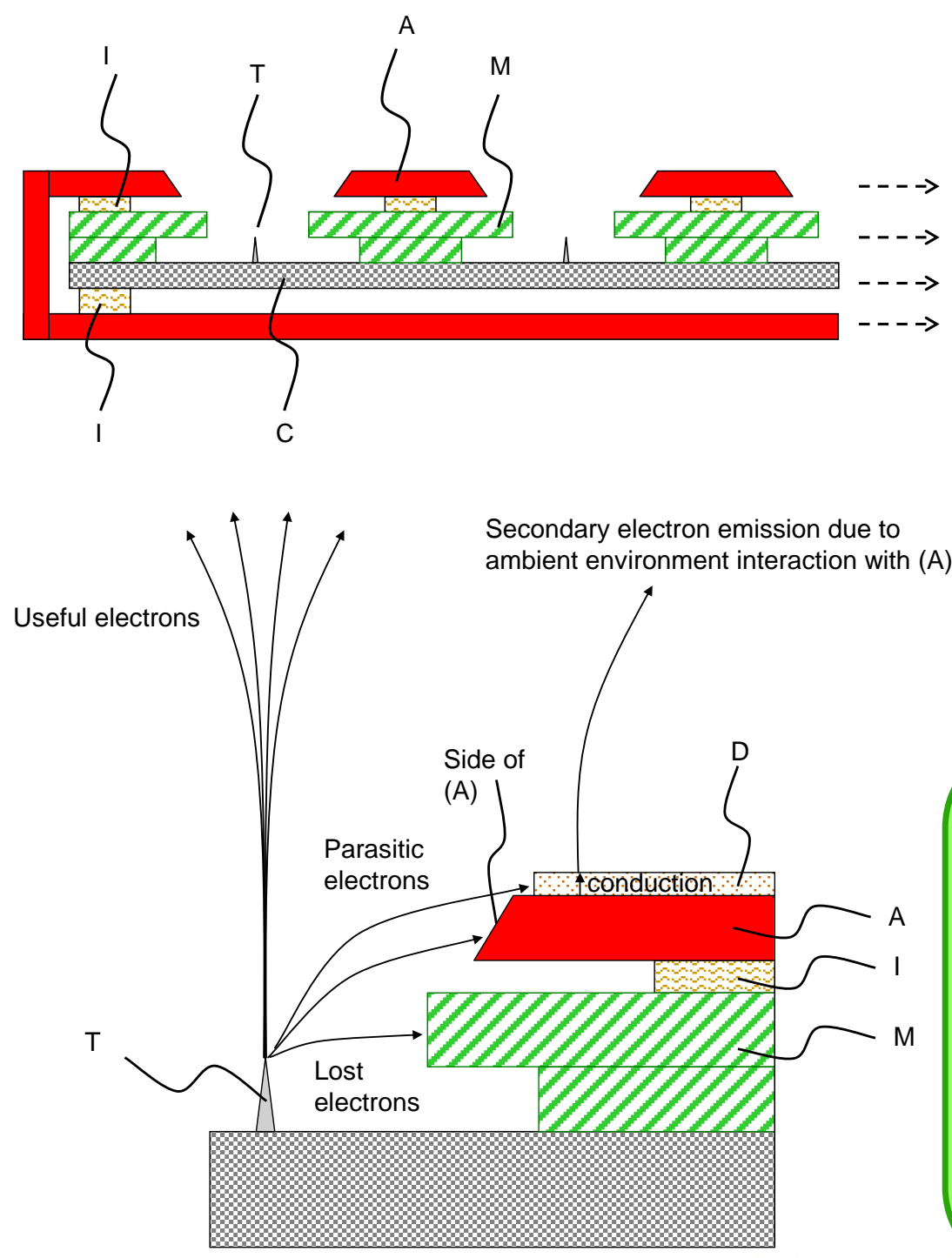
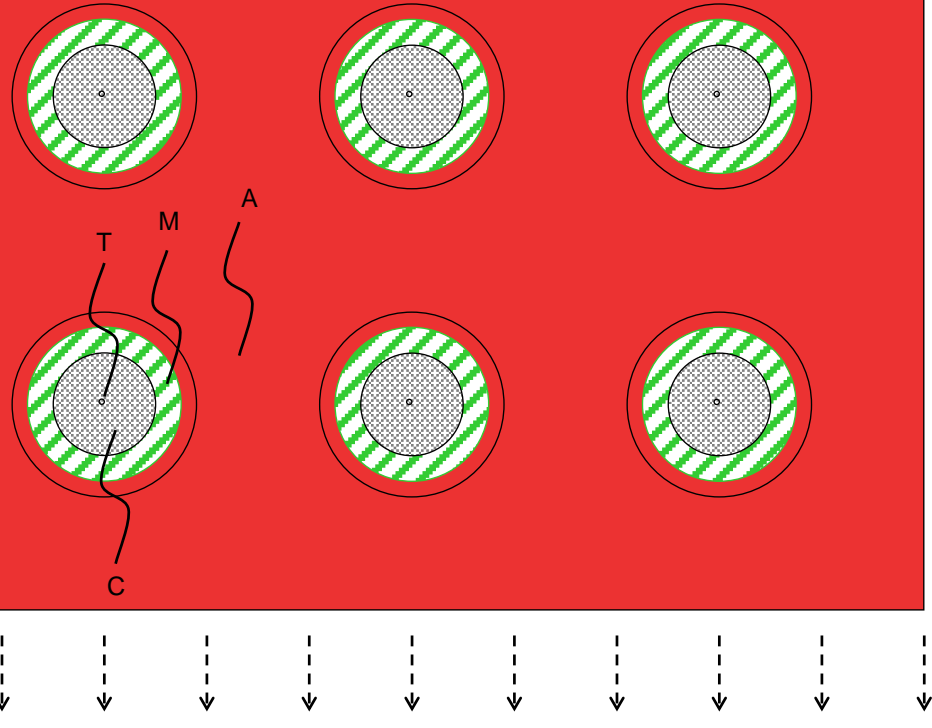

\section{Main points}

Cathode: tip covered with CNT

Passive charge of anode: metal covered with thin dielectric layer, enveloping anode

Global efficiency of electron emission: mask, shaped conductive anode, location on SC 


\section{CNT covered Cathode Tip}

- Multiply electric field amplification

- Tip Factor = Length / Radius up to 10-100

- CNT factor = up to 2500 from literature

- Challenge $=$ make CNT grow on a tip (recent advances in this field in literature)
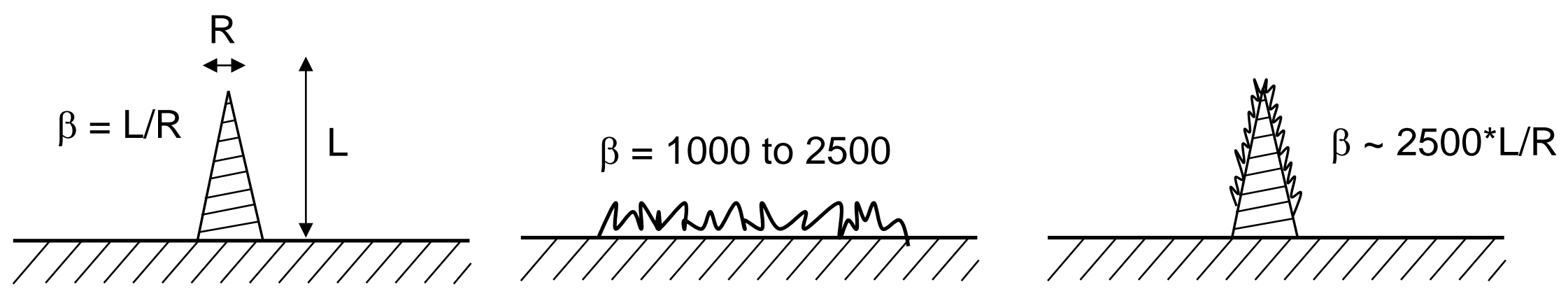


\section{Anode Design Specifications}

- Positive charging only by passive means

- Ambient electron impact (SEEE)

- Photoemission

- Appropriate materials

- Generally dielectrics

- Use of a thin layer to preserve electrical conduction

- Candidates: diamond, Indium Tin Oxide

- Sandwish structure

- Conductive basis (metal)

- Thin layer on top to benefit from

- emission

- conduction

- Advantages
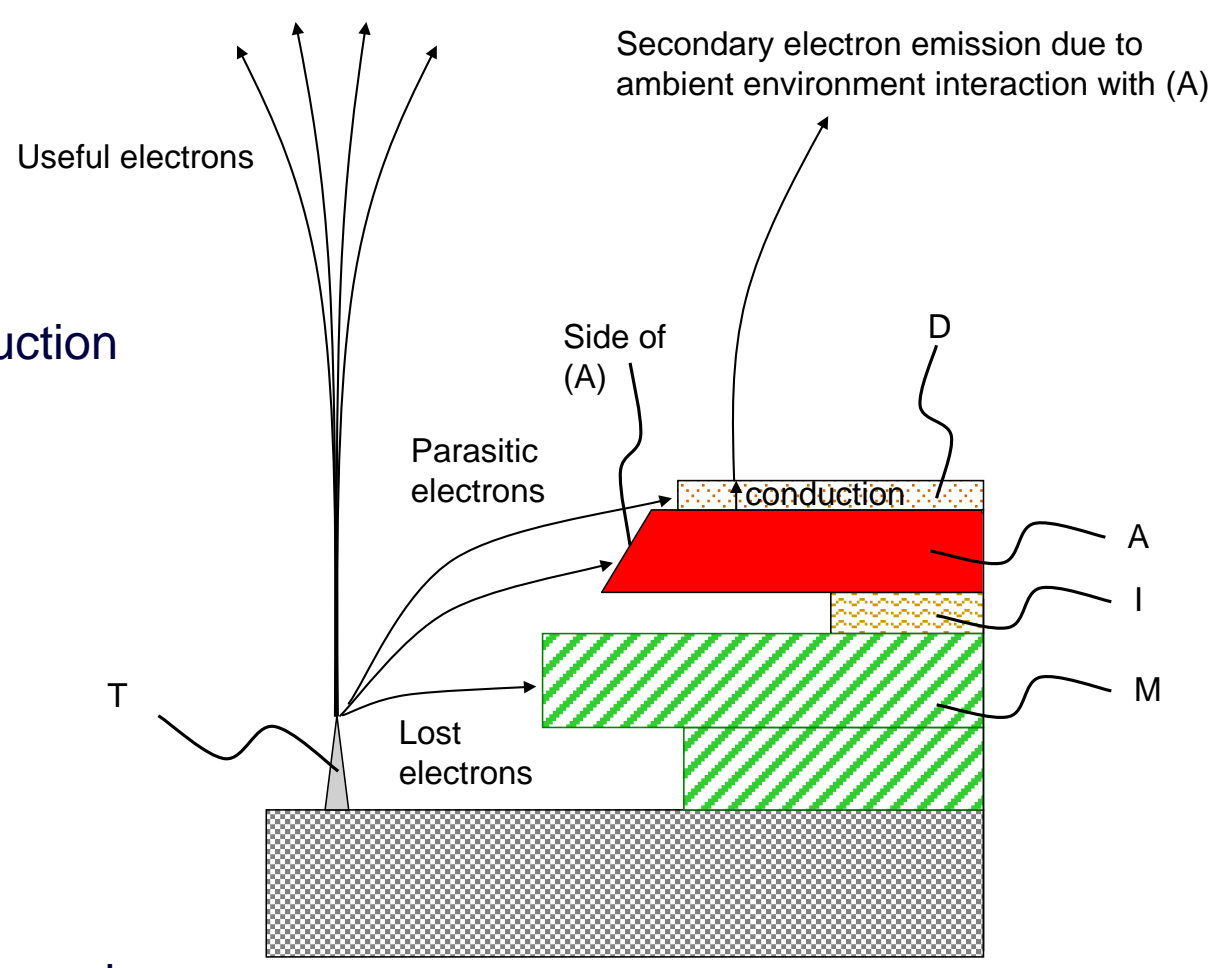

- Avoid recollection of cathode electrons by the anode

- Maintain anode/cathode voltage

- Mask = Avoid recollection by anode 


\section{Enveloping Anode}

- Anode envelops the system

- Optimize positive charging whatever the Sun direction

- Covered with a material with good SEEE and photoemission

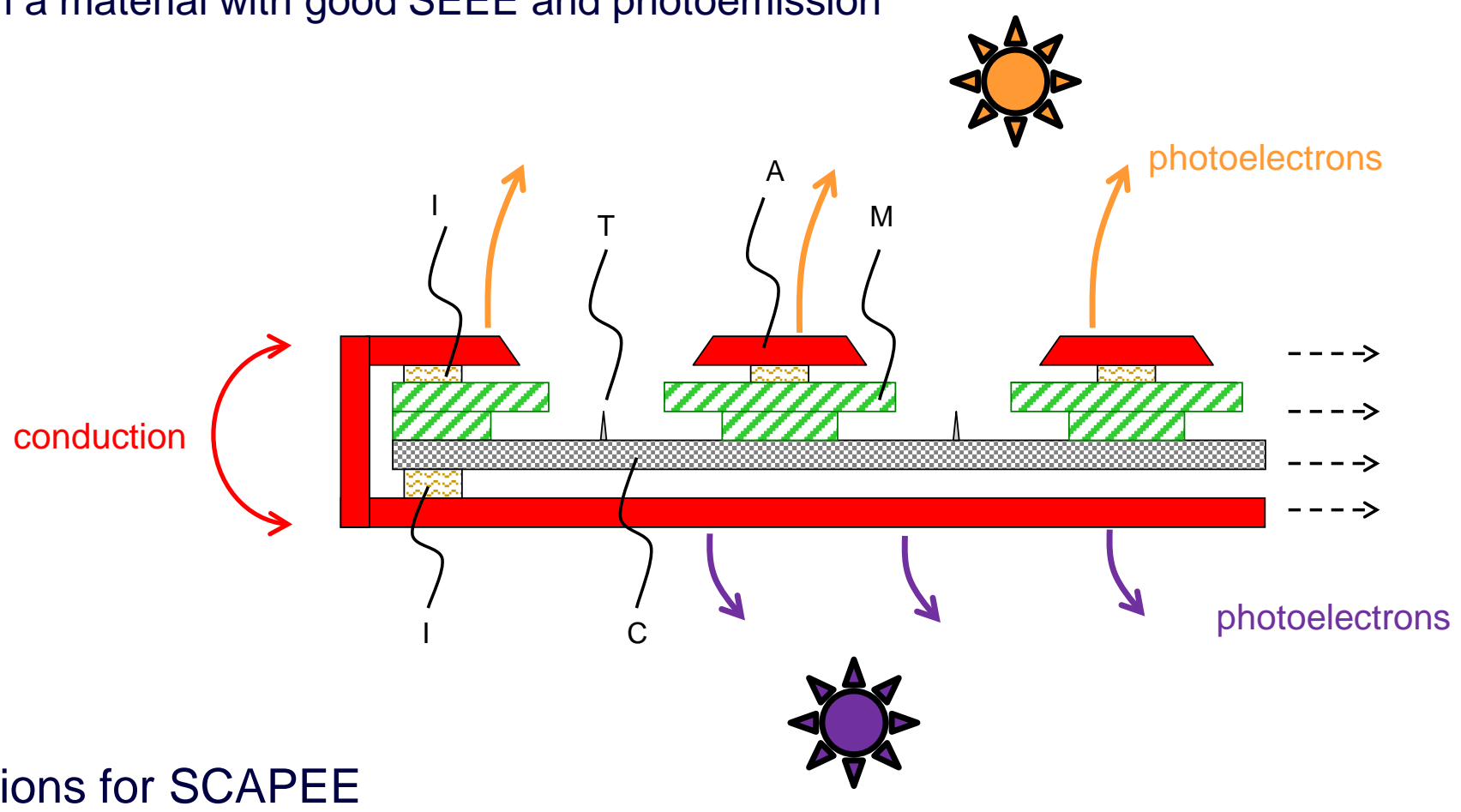

- Preferred locations for SCAPEE

- Close to less negative surfaces $\rightarrow$ end of solar arrays

- Far enough from most negative spacecraft surfaces $\rightarrow$ end of long booms 


\section{Numerical Assessment at Micron Scale}

- Parametric study

- Cathode dimensions

- Anode shape and dimensions

- Mask position

- Use of SPIS, the Spacecraft Plasma Interaction Software

- Initial configuration = loss of electrons on the anode

$\rightarrow$ not possible to maintain the anode voltage $\rightarrow$ inefficient
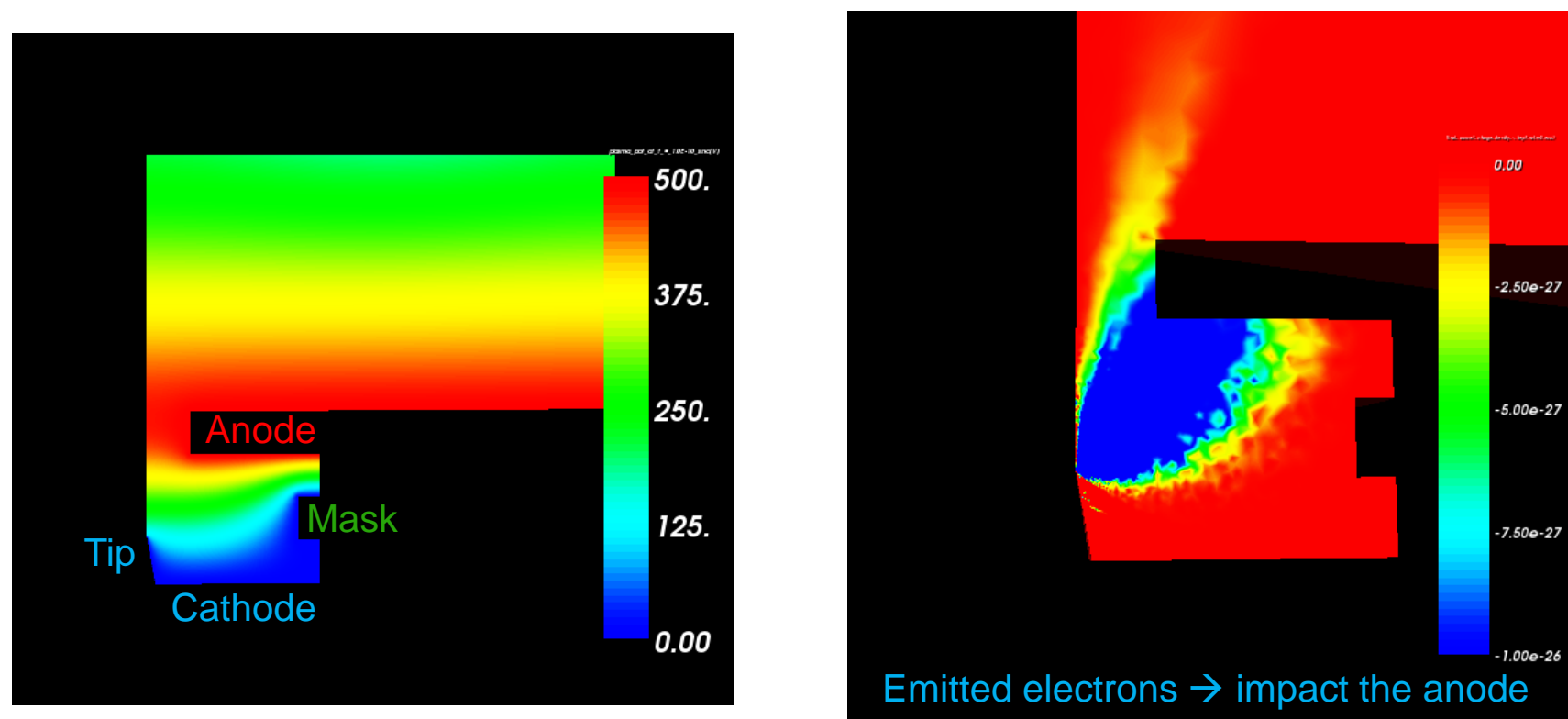


\section{Optimized configuration}

- Electrostatic lens

- Prevent electron recollection by anode

- Electron converge and then diverge

- Need larger electric field amplification at the tip
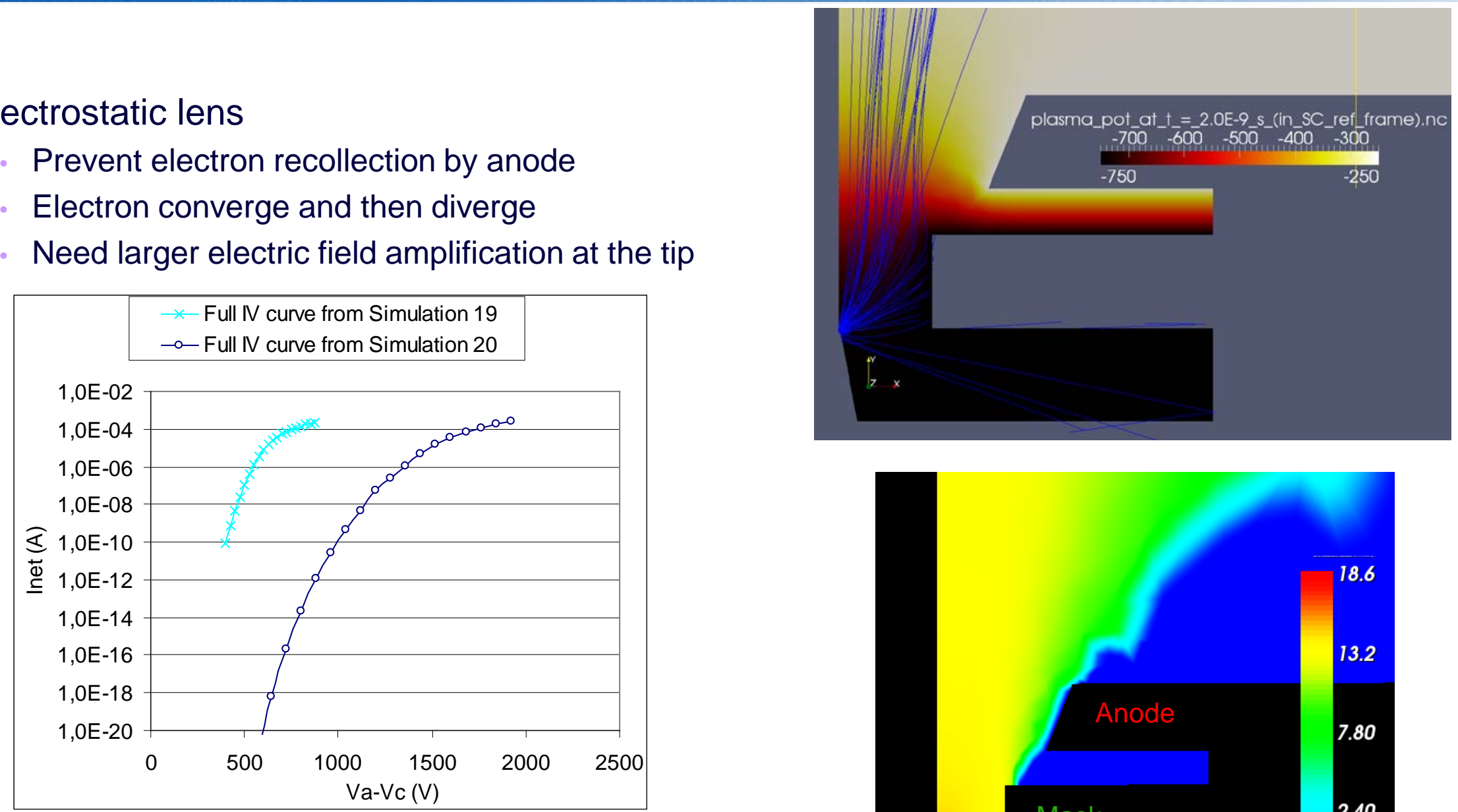

Currents of some fraction of milliAmp

Space charge effect when the current increases

Linear increase with anode/cathode voltage, instead of exponential

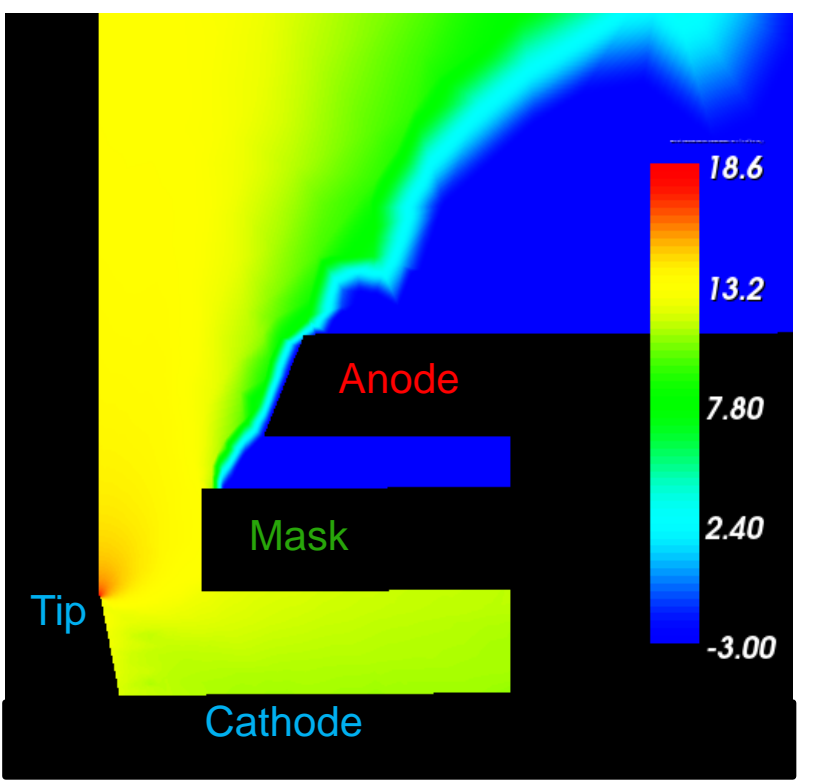




\section{Assessment at Spacecraft Scale}

- GEO environment from ECSS worst case for surface charging
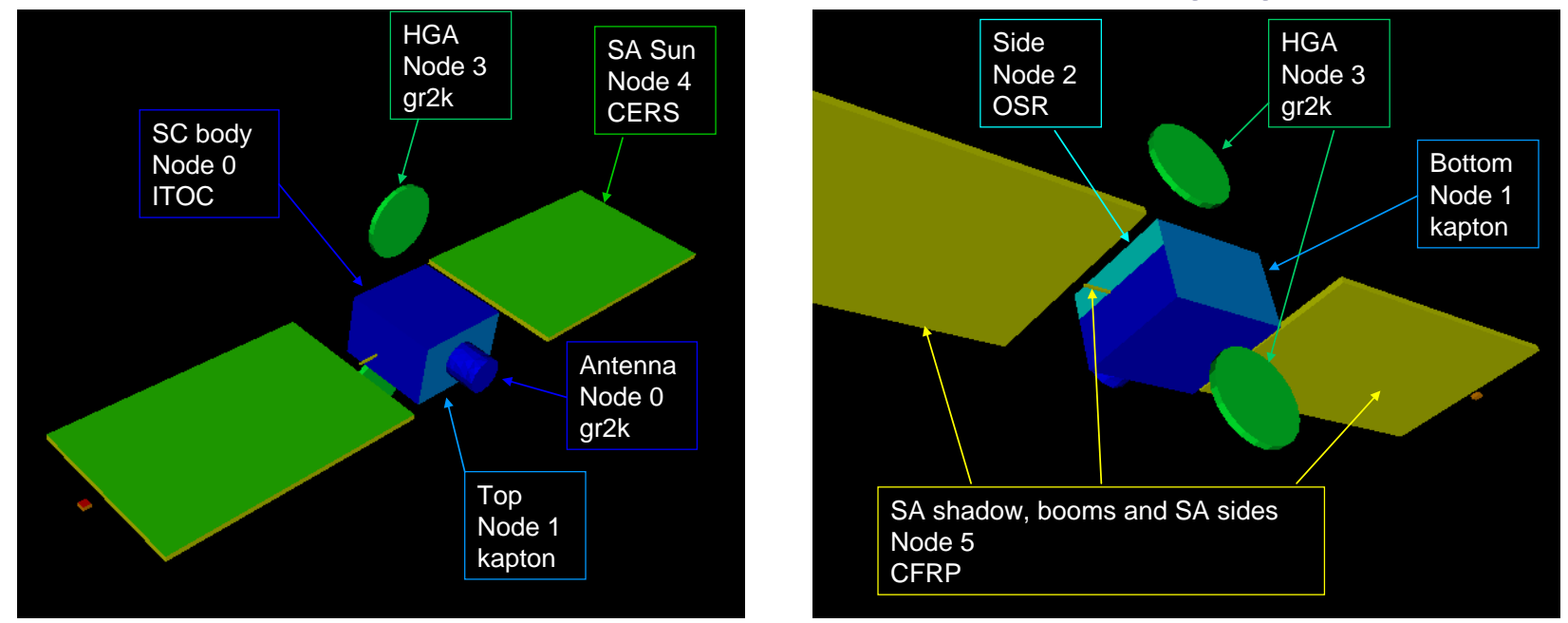

- Reference results without SCAPEE at $\mathrm{t}=1000 \mathrm{~s}$

\begin{tabular}{|l|l|l|l|}
\hline & Ground & $\begin{array}{l}\text { Cover } \\
\text { glasses }\end{array}$ & Anode \\
\hline Absolute pot & $-5400 \mathrm{~V}$ & $-3200 \mathrm{~V}$ & N/A \\
\hline Differential pot & 0 & $+2200 \mathrm{~V}$ & \\
\hline
\end{tabular}

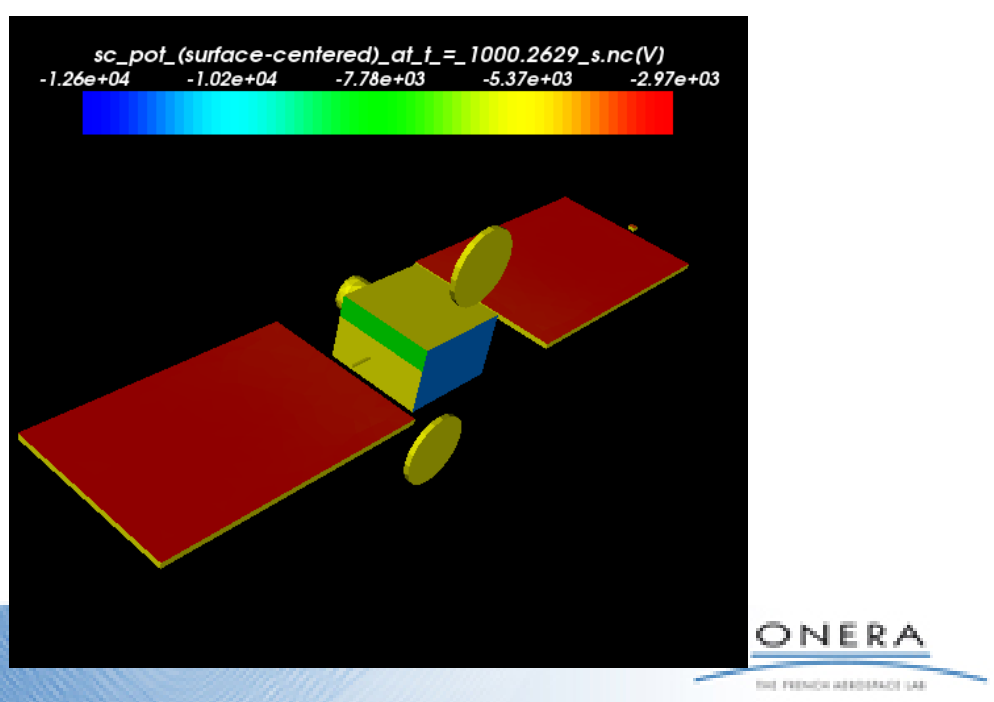




\section{SCAPEE away from SA}

- System located 2 meters away from SA

- Avoid the barriers of potential imposed by the negative spacecraft surfaces

- Anode tends to float positive wrt all other SC surfaces

- Significant reduction in cover glass potential
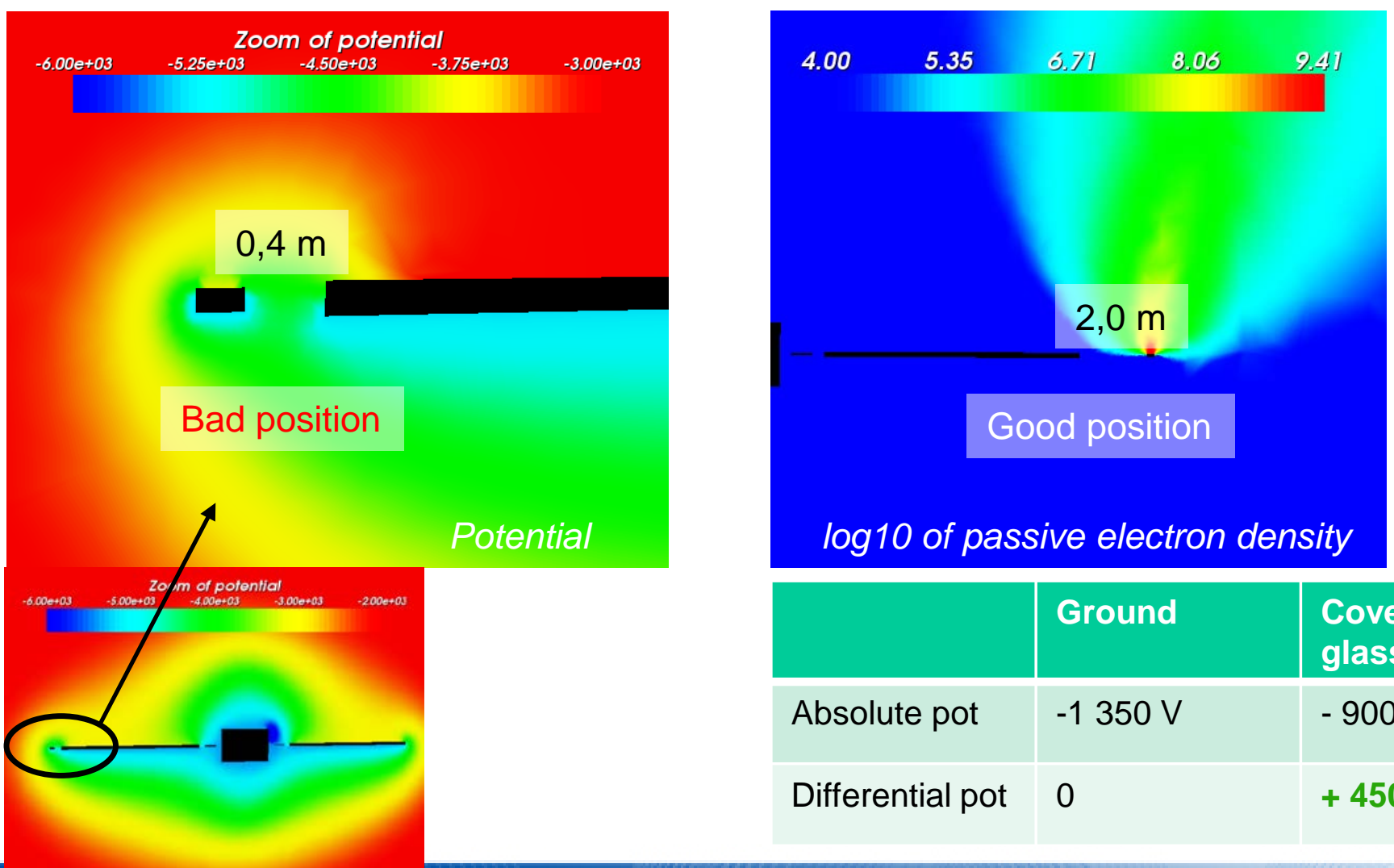

\begin{tabular}{|l|l|l|l|}
\hline & Ground & $\begin{array}{l}\text { Cover } \\
\text { glasses }\end{array}$ & Anode \\
\hline Absolute pot & $-1350 \mathrm{~V}$ & $-900 \mathrm{~V}$ & $-650 \mathrm{~V}$ \\
\hline Differential pot & 0 & $+450 \mathrm{~V}$ & $+700 \mathrm{~V}$ \\
\hline
\end{tabular}




\section{SCAPEE on top of spacecraft}

- Facing the Sun on top of spacecraft (for instance at the end of a boom, not illustrated)
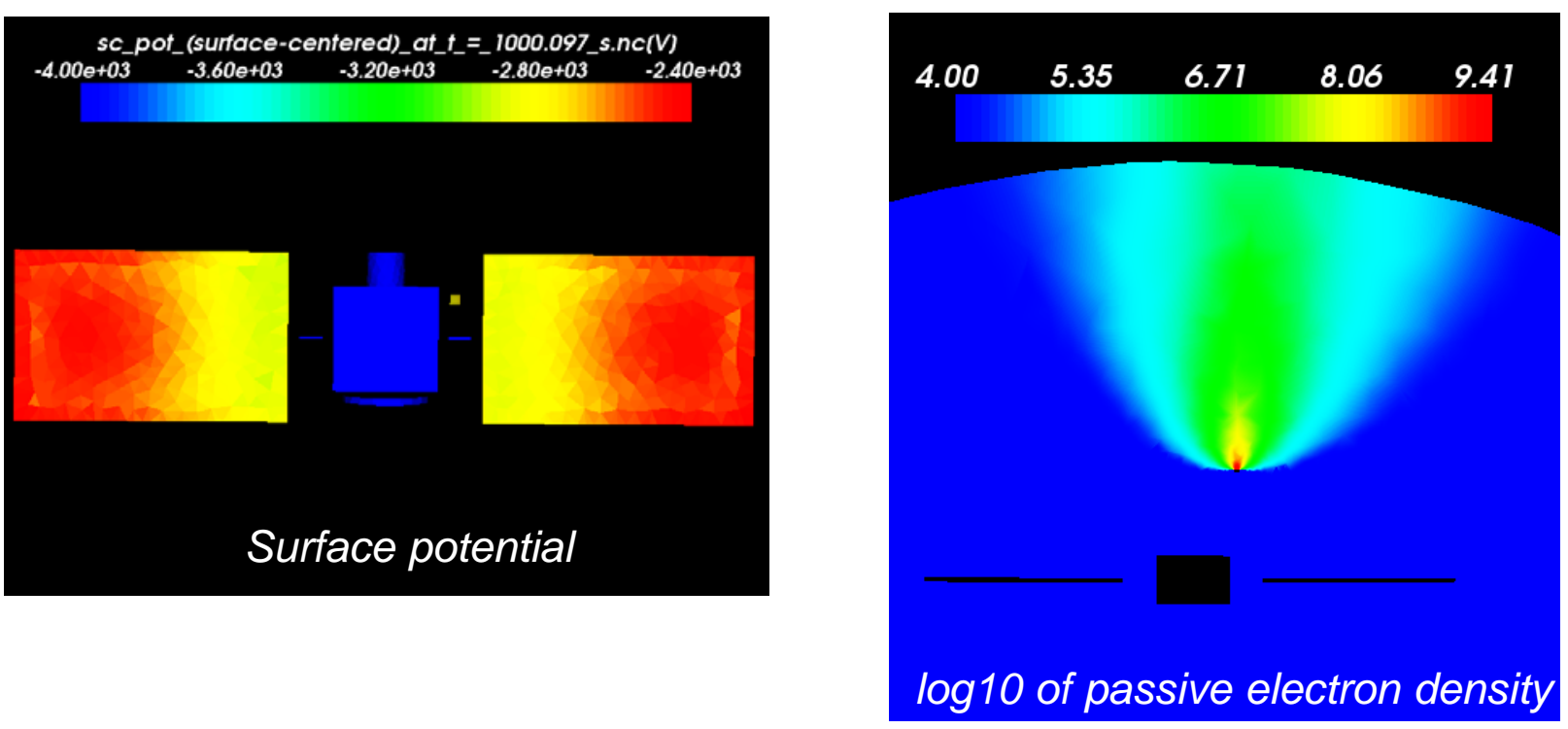

\begin{tabular}{|l|l|l|}
\hline Ground & $\begin{array}{l}\text { Cover } \\
\text { glasses }\end{array}$ & Anode \\
\hline
\end{tabular}

\begin{tabular}{l|l|l|l} 
Absolute pot & $-2150 \mathrm{~V}$ & $-1400 \mathrm{~V}$ & $-1500 \mathrm{~V}$
\end{tabular}

\begin{tabular}{l|l|l|l} 
Differential pot 0 & $+750 \mathrm{~V}$ & $+650 \mathrm{~V}$
\end{tabular}

Anode charging is not as good as before Solution = SCAPEE at the end of a long boom 


\section{SCAPEE firing the SA}

- No difference in solar array potential

- Probably less efficient system
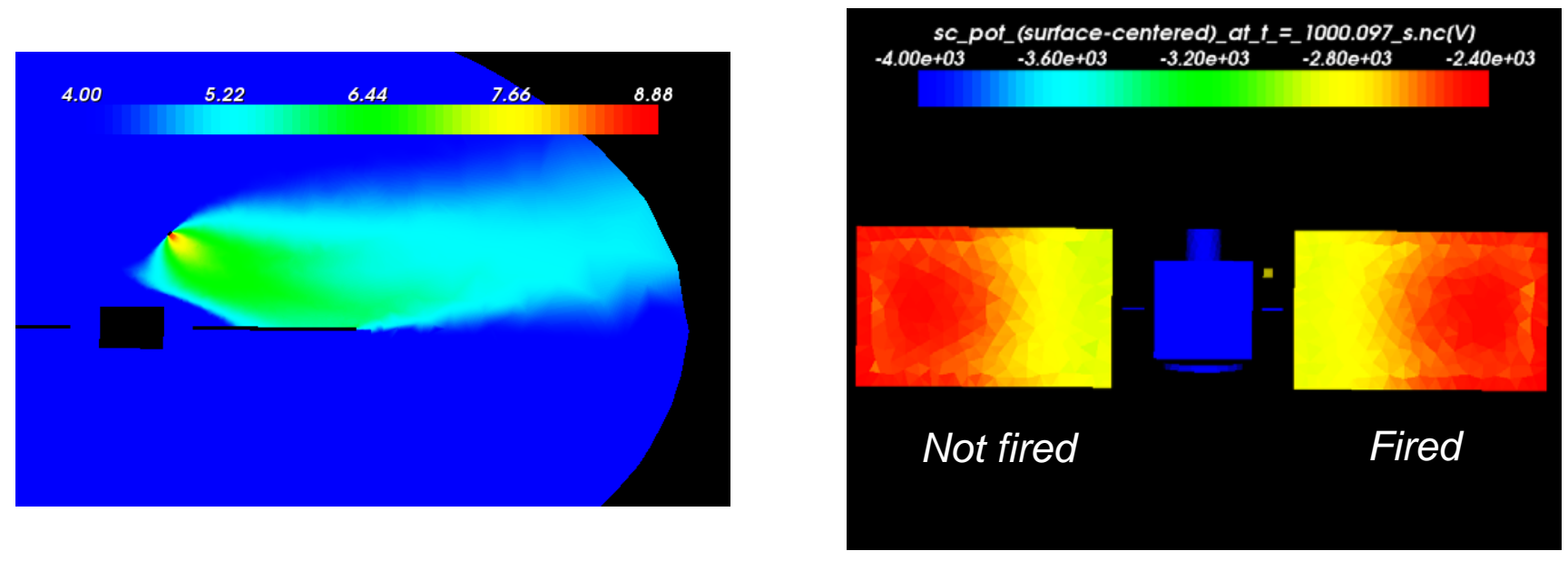


\section{Summary}

- Concept assessed at micron and spacecraft scale by numerical study

- Combines

- Sub-micron structure of the cathode

- Anode shape and covering layer

- Mask

- Fully passive method

- Importance of location on-board

- Next steps

- Prototype

- Test under space like condition

- Ageing and thermal cycling effect 